\title{
Design and development of a two-color emissive FRET pair based on a photostable fluorescent deoxyuridine donor presenting a mega-Stokes shift
}

Nicolas P. F. Barthes, ${ }^{a}$ Krishna Gavvala, ${ }^{b}$ Dominique Bonhomme, ${ }^{a}$ Anne Sophie Dabert-Gay, ${ }^{c}$

Delphine Debayle, ${ }^{\mathrm{c}}$ Yves Mély, ${ }^{\mathrm{b}}$ Benoît Y. Michel, ${ }^{\mathrm{a}}$ Alain Burger*a

a) Institut de Chimie de Nice, UMR 7272, Université Côte d'Azur, CNRS, Parc Valrose, 06108 Nice Cedex 2, France

b) Laboratoire de Biophotonique et Pharmacologie, UMR 7213, Faculté de Pharmacie, Université de Strasbourg, CNRS, 74 Route du Rhin, 67401 Illkirch, France

c) Institut de Pharmacologie Moléculaire et Cellulaire, UMR 6097, Université de Nice Sophia Antipolis, 660 Route des Lucioles, 06560 Valbonne, France

Correspondingauthors: burger@unice.fr ; benoit.michel@unice.fr 


\section{Table of contents}

Supporting Information

1. ODN synthesis, purification \& physical characterizations...........................3

1.1 ODN labeling and purification..........................................................3

1.2 MALDI-TOF/TOF analysis of ODNs..............................................4

2. Spectroscopic characterizations.....................................................................6

2.1 Denaturation studies and melting temperatures...............................6

2.2 Circular dichroism..............................................................................8

2.3 Absorbance and Fluorescence spectra............................................8

3. NMR spectra..............................................................................................12

NMR spectra of compounds:

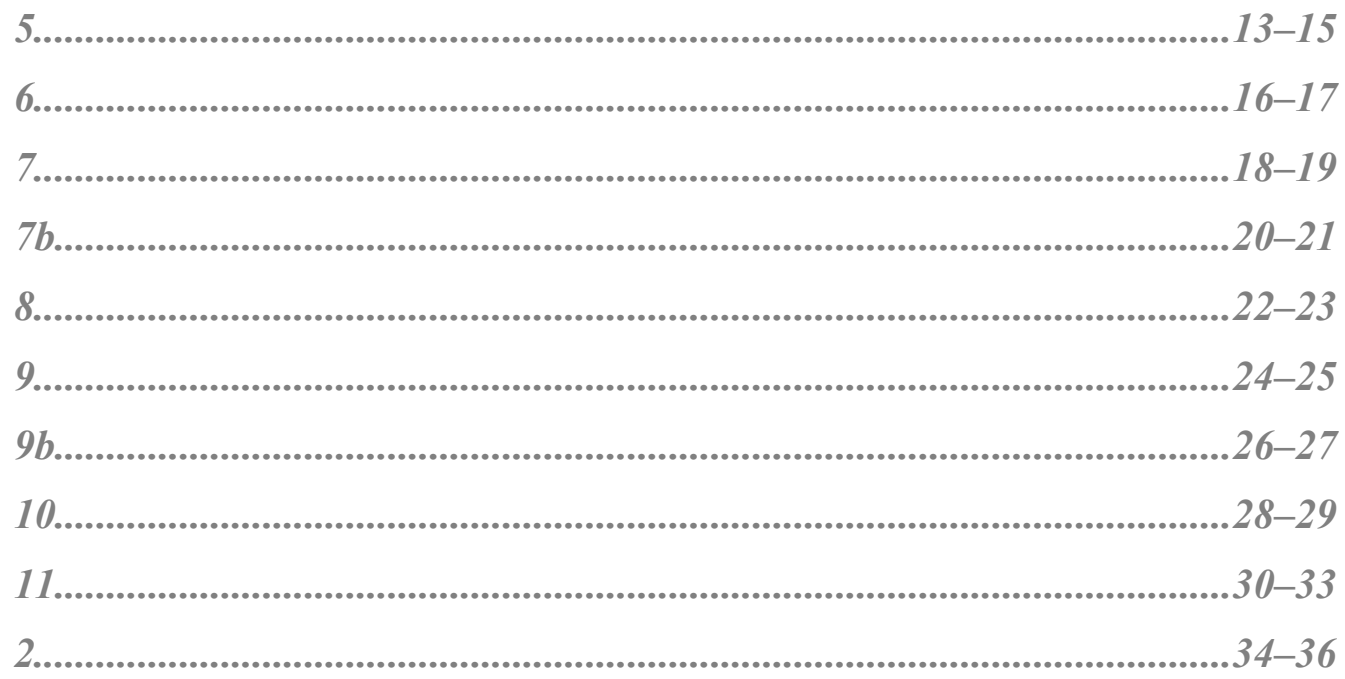




\section{Supporting Information}

\section{ODN synthesis, purification \& physical characterizations}

1.1 ODN labeling and purification:

Fig S1. Structure of the 5'-terminal Cy3 flexible linker used in this study

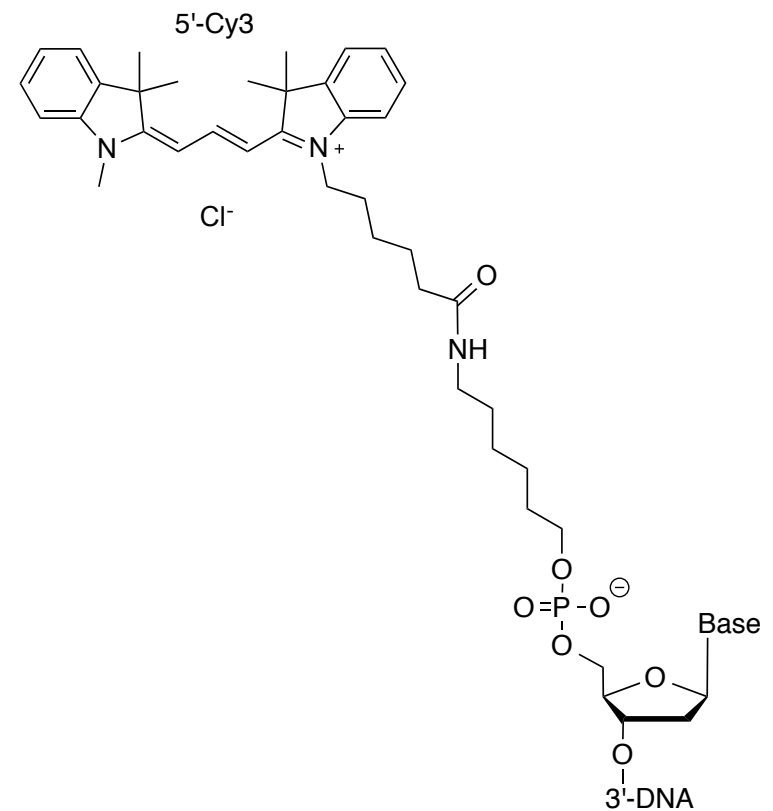

Fig S2. HPLC profile of DNA1 single strand ODN (254 nm left-390 nm right)

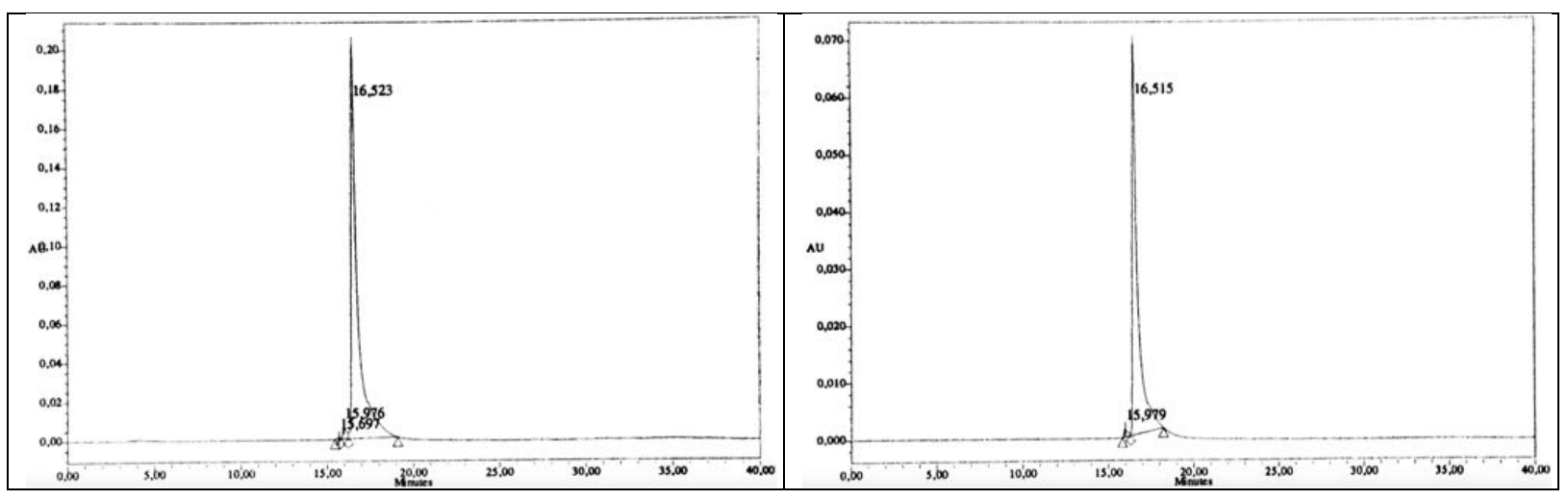

Fig S3. HPLC profile of DNA3 single strand ODN (254 nm left - $390 \mathrm{~nm}$ right)
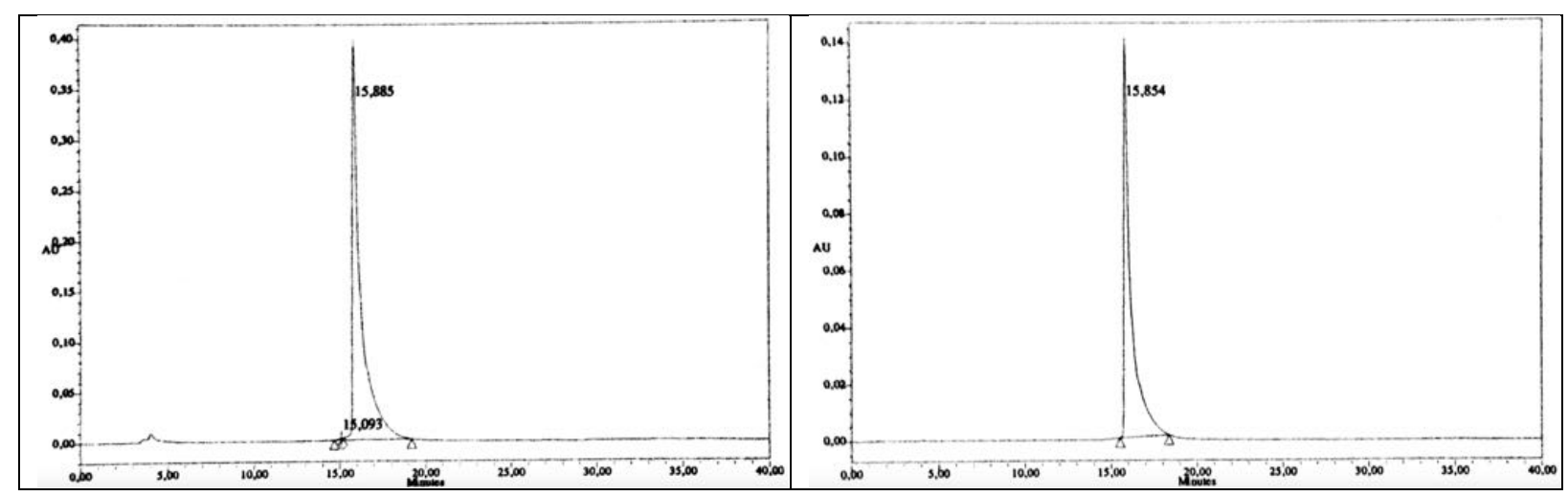
Fig S4. HPLC profile of DNA5 single strand ODN (254 nm left-390 nm right)

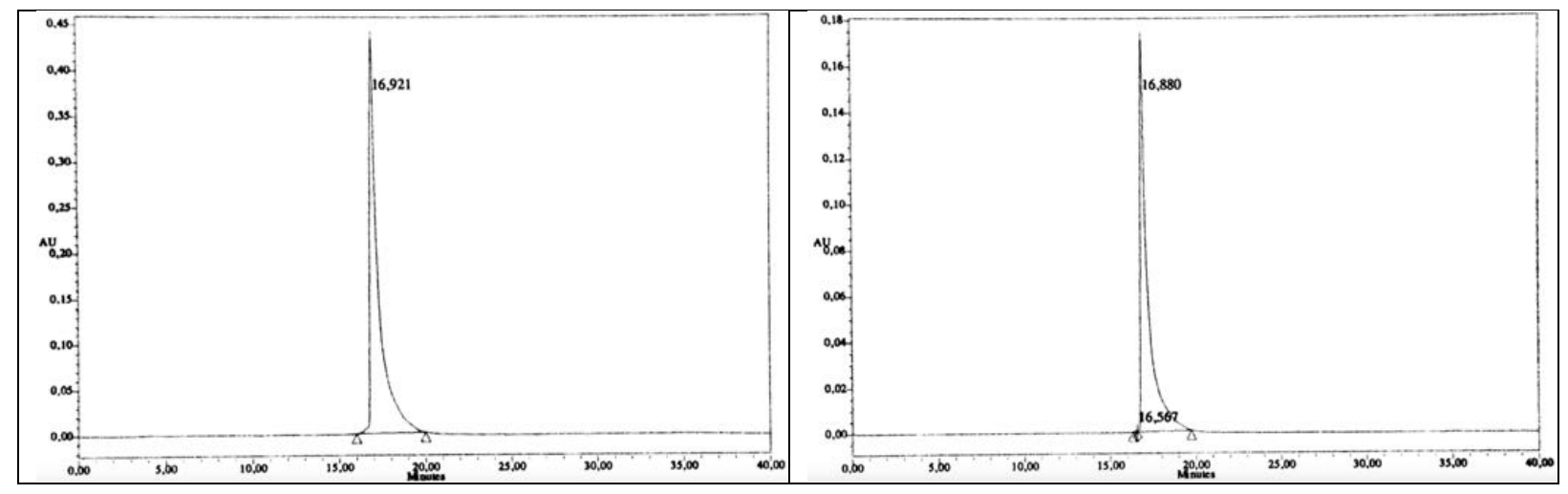

Fig S5. HPLC profile of DNA7 single strand ODN (254 $\mathrm{nm}$ left $-390 \mathrm{~nm}$ right)

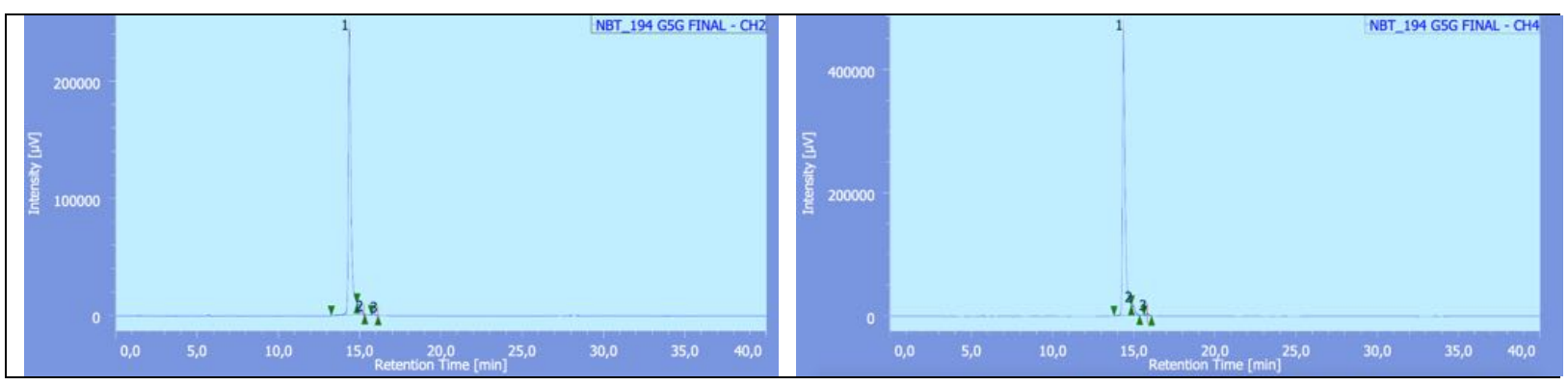

Fig S6. HPLC profile of DNA9 single strand ODN (254 $\mathrm{nm}$ left - $550 \mathrm{~nm}$ right)

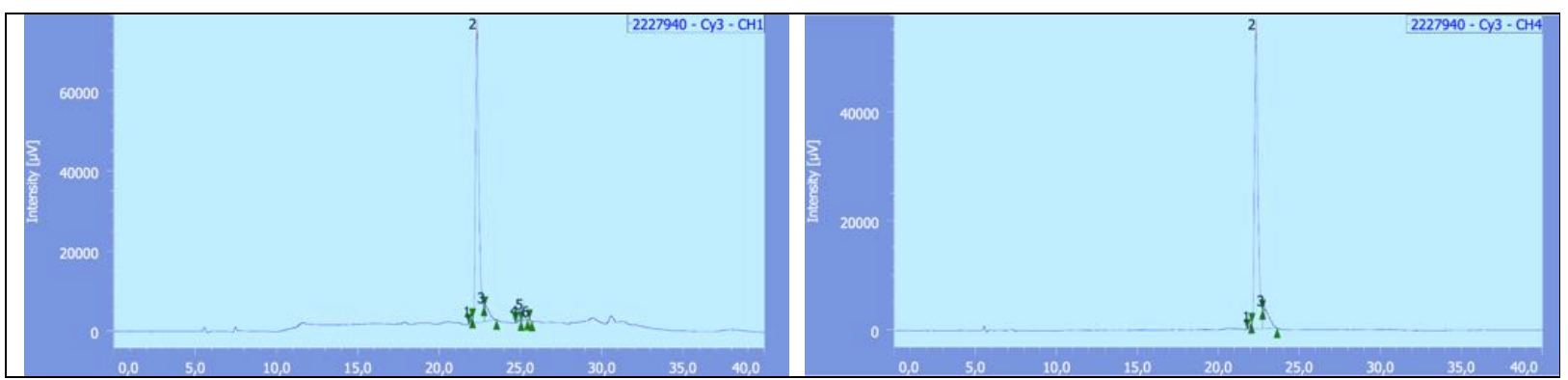

\subsection{MALDI-TOF/TOF analysis of ODNs:}

Table S1. Mass of the synthesized oligonucleotides.

\begin{tabular}{ccc}
\hline DNA & Sequence & $\begin{array}{c}\text { MALDI-TOF } \\
\text { found (calcd) }\left[\mathbf{M}^{+}\right]\end{array}$ \\
\hline $\mathbf{1}$ & 5'd-CGTTTTTMTTTTTGC-3' $^{\prime}$ & $4787.6(4787.2)$ \\
$\mathbf{3}$ & 5'd-CGTTTTAMATTTTGC-3' $^{\prime}$ & $4806.3(4805.5)$ \\
$\mathbf{5}$ & 5'd-CGTTTTCMCTTTTGC-3' $^{\prime}$ & $4757.6(4757.2)$ \\
$\mathbf{7}$ & 5'd-CGTTTTGMGTTTTGC-3' & 4837.4 (4837.2) \\
$\mathbf{9}$ & 5'd-Cy3-GCAAAAAAAAAAACG-3' $^{\prime}$ & 5245.5 (5233.5) \\
\hline
\end{tabular}


Fig S7. MALDI-TOF mass spectrograms of labeled ODN sequences (DNA1, DNA3, DNA5, DNA7, DNA9)

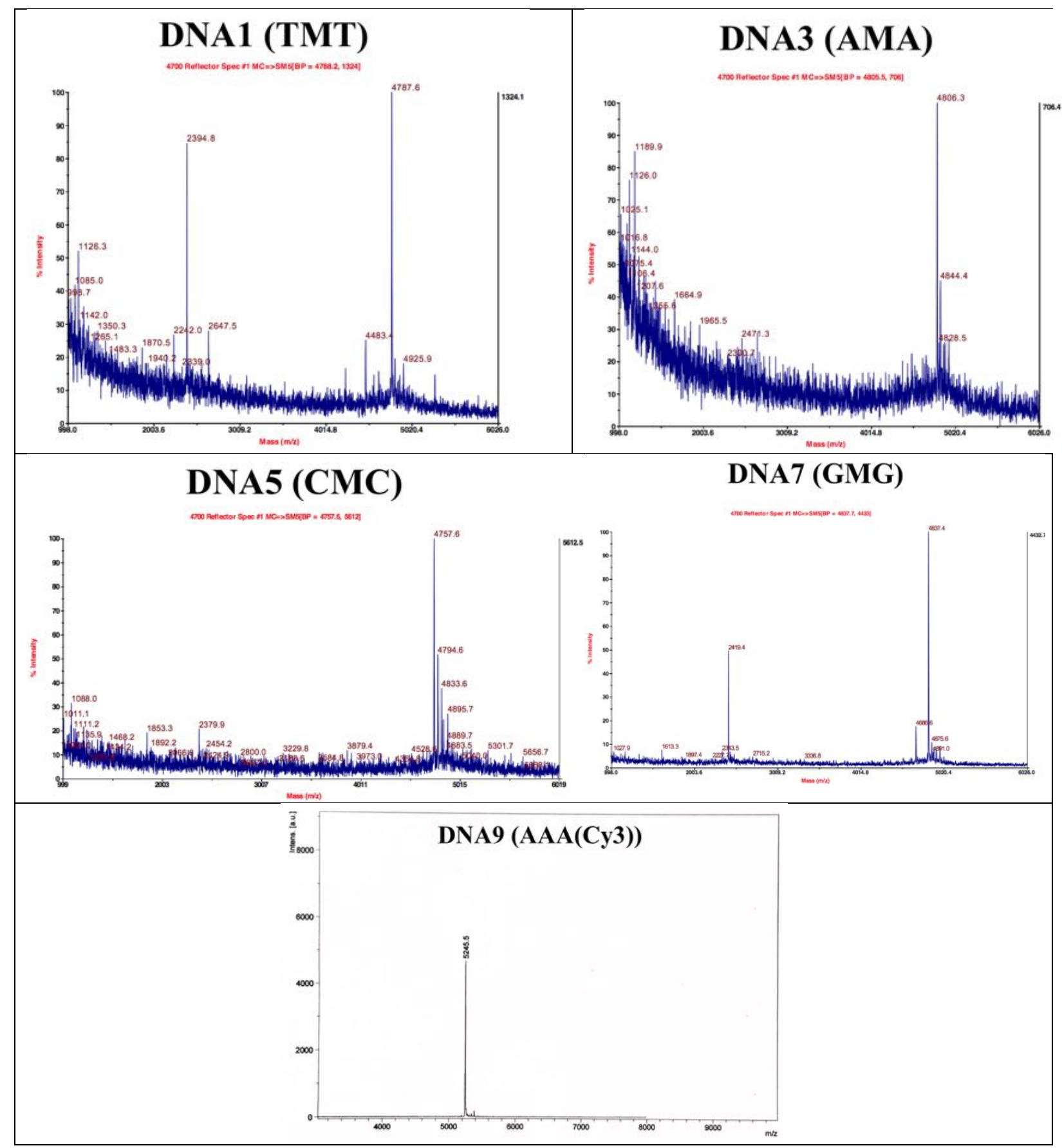




\section{Spectroscopic characterizations}

\subsection{Denaturation studies and melting temperatures}

Table S2. Melting temperatures of the duplexes. ${ }^{a}$

\begin{tabular}{|c|c|c|c|c|}
\hline \multirow{2}{*}{ DNA } & \multirow{2}{*}{ Duplexes } & \multicolumn{3}{|c|}{$\operatorname{Tm}\left({ }^{\circ} \mathrm{C}\right)$} \\
\hline & & Labeled & Wild Type ${ }^{a}$ & $\Delta \operatorname{Tm}\left({ }^{\circ} \mathrm{C}\right)^{b}$ \\
\hline \multirow[t]{4}{*}{2} & ТМТ- $A A A$ & 45.2 & 49.5 [50.2] & -4.3 \\
\hline & ТМТ-ATA & 37.5 & 40.5 [42.2] & -3.0 \\
\hline & ТМТ- $A C A$ & 39.5 & 39 [42] & 0.5 \\
\hline & ТМТ- $A G A$ & 37.5 & 40.7 [42.9] & -3.2 \\
\hline \multirow[t]{4}{*}{4} & AMA-TAT & 43.1 & $47.3[47.4]$ & -4.2 \\
\hline & AMA-TTT & 36.9 & 39.8 [40.6] & -2.9 \\
\hline & AMA- $T C T$ & 39.2 & 38.5 [39.3] & 0.7 \\
\hline & AMA- $T G T$ & 35.9 & 42.7 [42.8] & -6.8 \\
\hline \multirow[t]{4}{*}{6} & СМC-GAG & 46.5 & 51.3 [53.7] & -4.8 \\
\hline & CMC-GTG & 37.9 & 41.1 [46.7] & -3.2 \\
\hline & CMC-GCG & 42.9 & $42.1[45.3]$ & 0.8 \\
\hline & СМС- $G G G$ & 41.9 & $46.5[49.5]$ & -4.6 \\
\hline \multirow[t]{4}{*}{8} & GMG- $C A C$ & 51.4 & $54.8[55.1]$ & -3.4 \\
\hline & GMG-CTC & 44.7 & $46.6[47.5]$ & -1.9 \\
\hline & GMG- $C C C$ & 49.5 & $43.5[44.8]$ & 6.0 \\
\hline & GMG- $C G C$ & 46.5 & $49.7[51]$ & -3.2 \\
\hline
\end{tabular}

\begin{tabular}{llccc}
\hline \multirow{2}{*}{ DNA } & Duplexes & \multicolumn{3}{c}{$T_{\mathrm{m}}\left({ }^{\circ} \mathrm{C}\right)$} \\
\cline { 3 - 5 } & & Labeled & Wild Type $^{a}$ & $\Delta T_{\mathrm{m}}\left({ }^{\circ} \mathrm{C}\right)^{b}$ \\
\hline $\mathbf{1 0}$ & TTT-AAA(Cy3) & 51.9 & $49.5[50.2]$ & 2.4 \\
$\mathbf{1 1}$ & TMT-AAA(Cy3) & 47.5 & $45.5^{c}$ & 2.0 \\
\hline
\end{tabular}

${ }^{a} \mathrm{Tm}$ of the corresponding duplex formed from unmodified ODNs and its theoretical values given in square brackets $;{ }^{b} \Delta T \mathrm{~m}$ refers to the difference of Tm between the labeled and wild type ODNs. ${ }^{c}$ Comparison with the $\mathbf{M}$ mono-labeled duplex.

Fig S8. Melting temperature curves of wild-type double strands

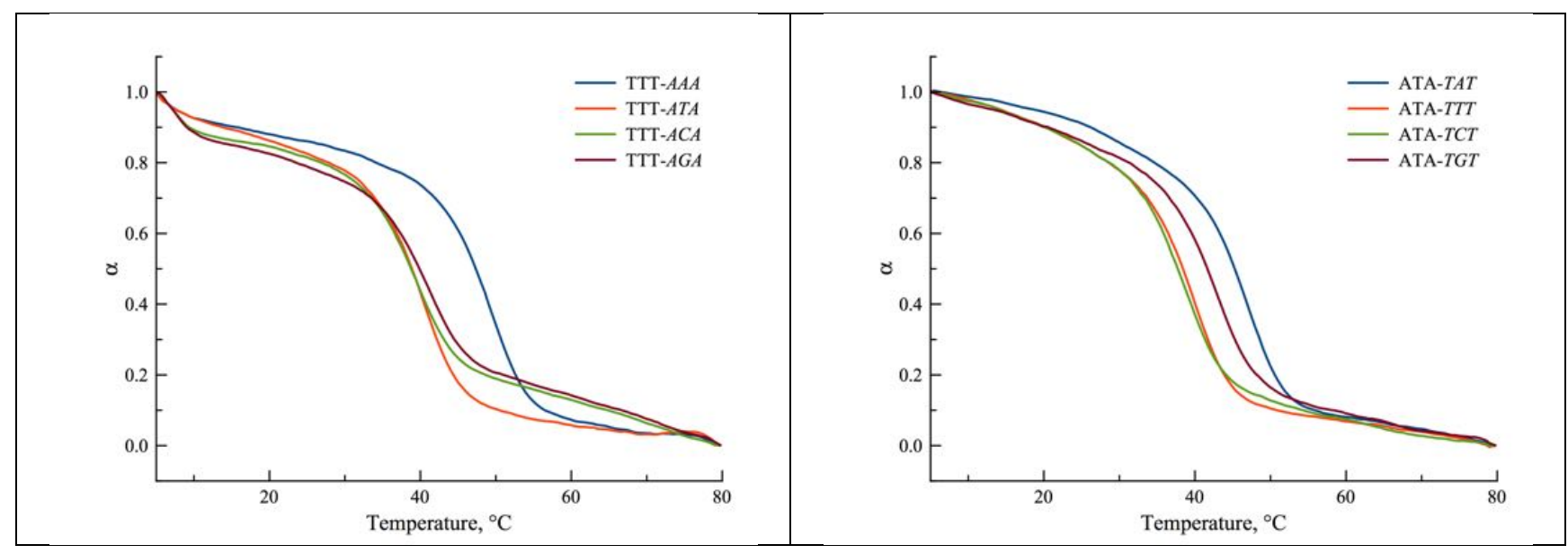

\footnotetext{
${ }^{1}$ Breslauer, K. J. Methods Enzymol. 1995, 259, 221.
} 

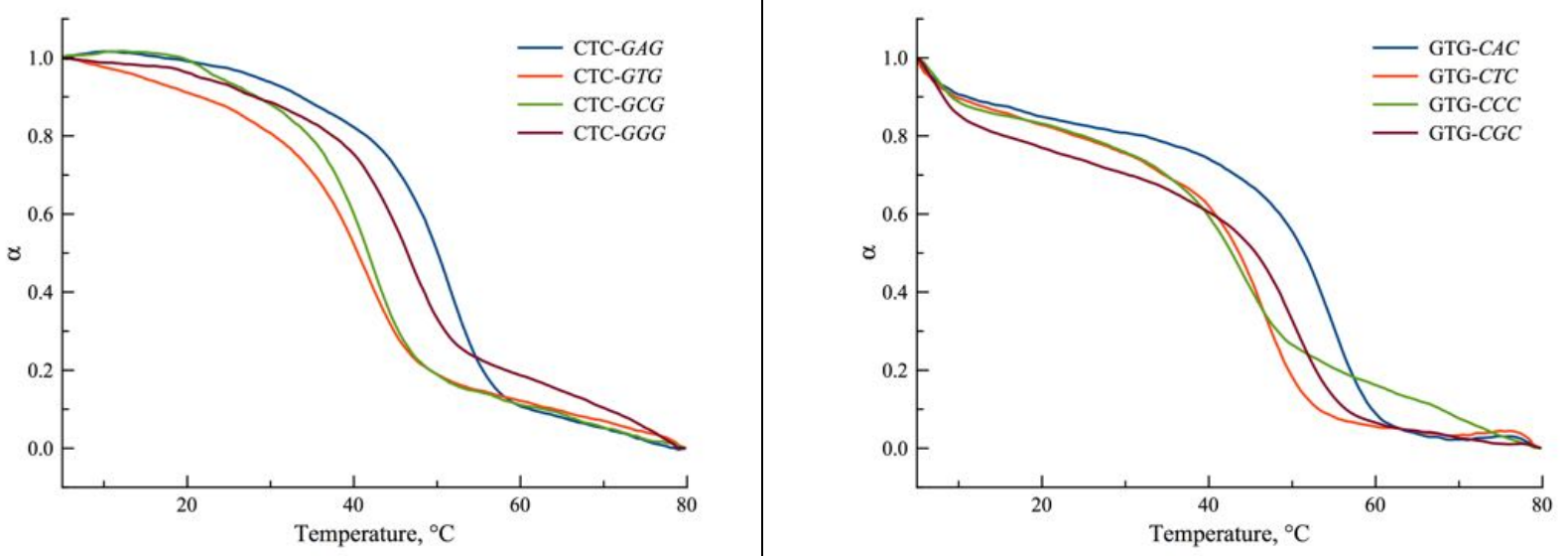

Fig S9. Melting temperature curves of labeled double strands

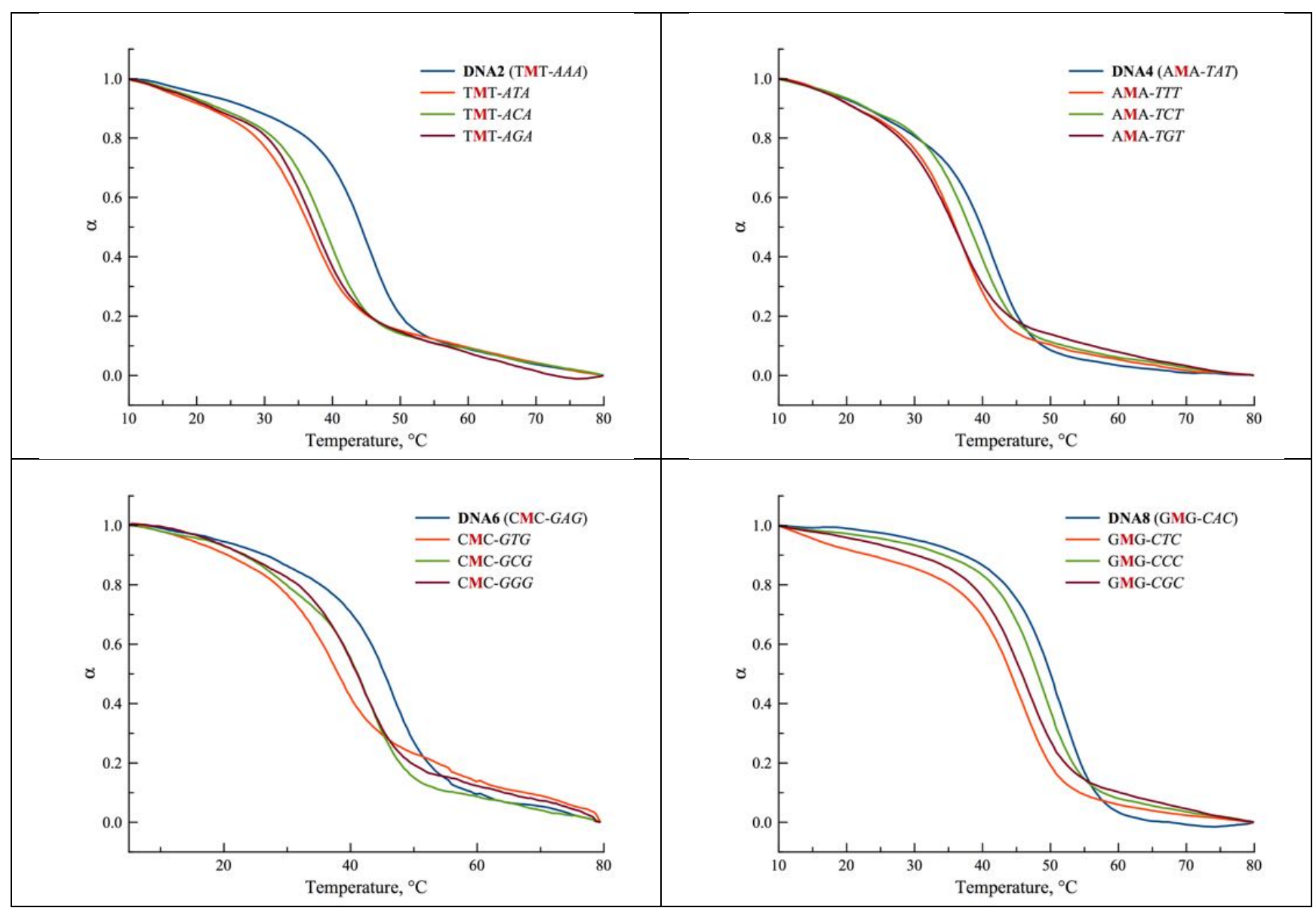




\subsection{Circular dichroism}

Fig S10. Representative CD spectra of wild-type and labeled duplexes

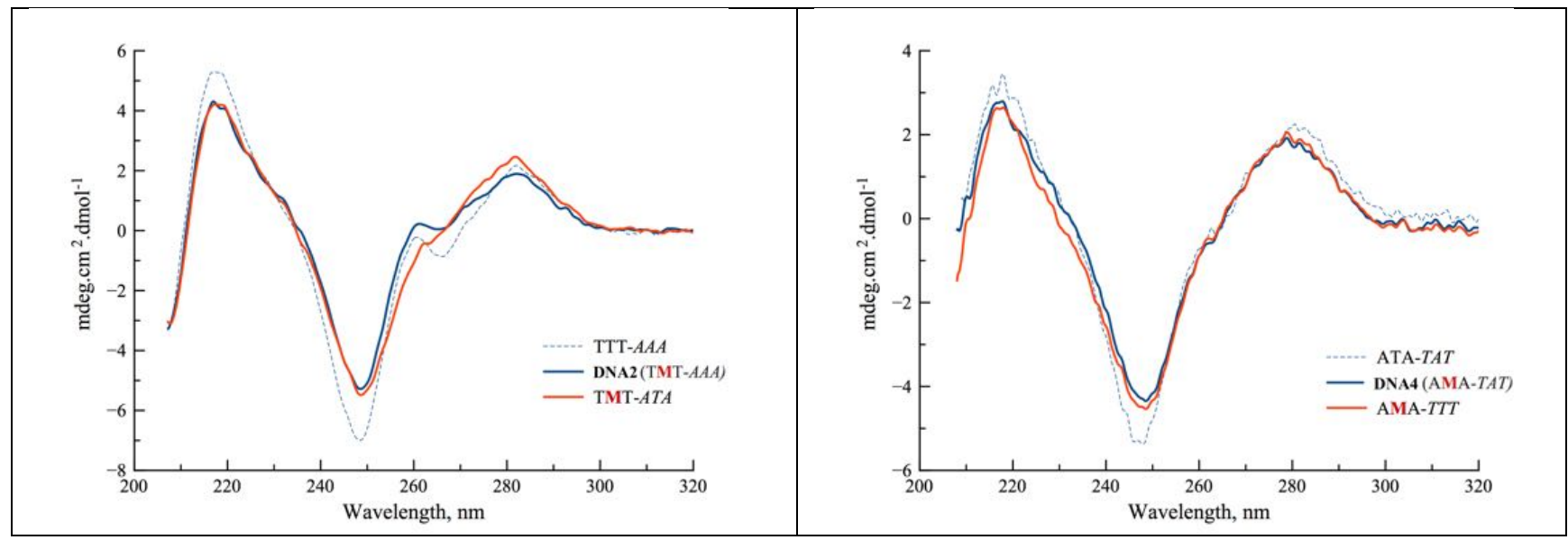

Fig S11. Representative CD spectra of wild type, Cy3 mono- and double-labeled duplexes

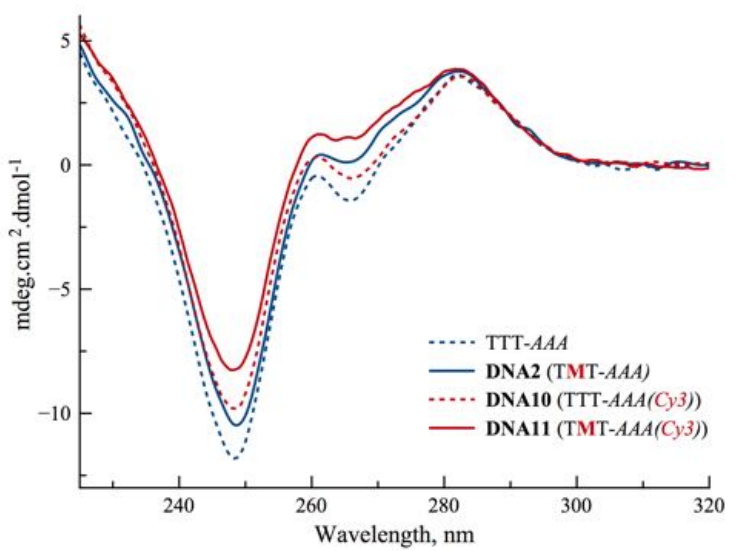

2.3 Absorbance and Fluorescence spectra

Fig S12. UV spectra of labeled single and match double strands
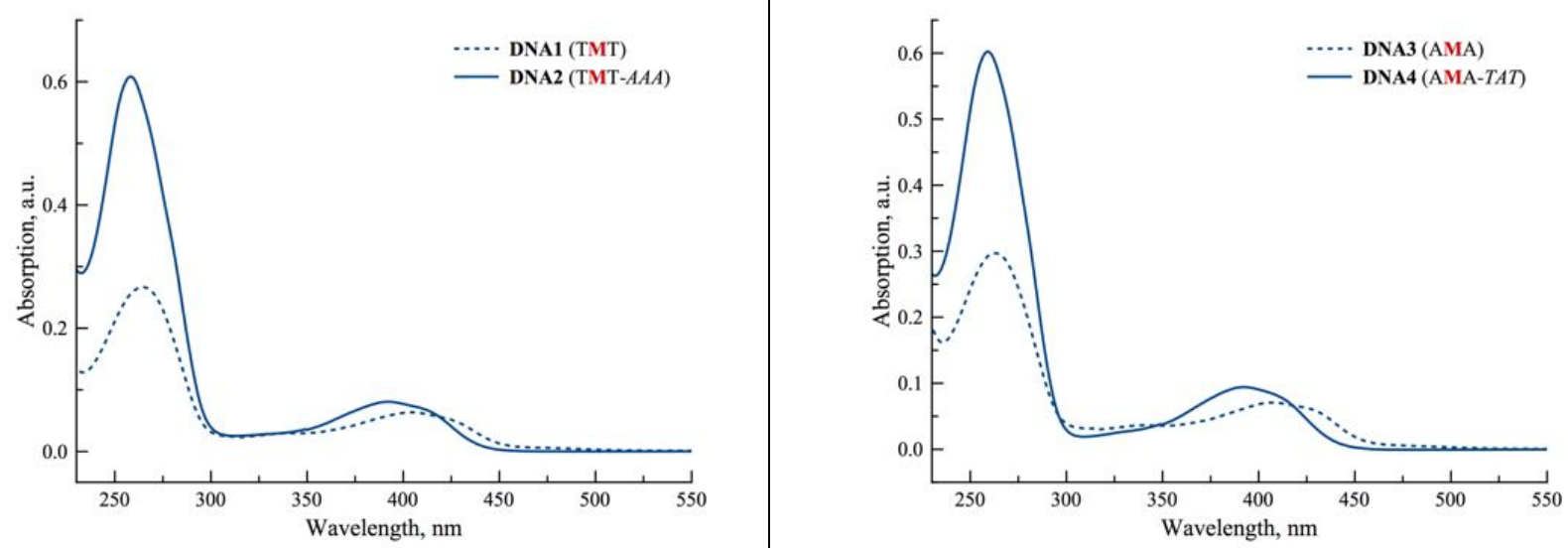


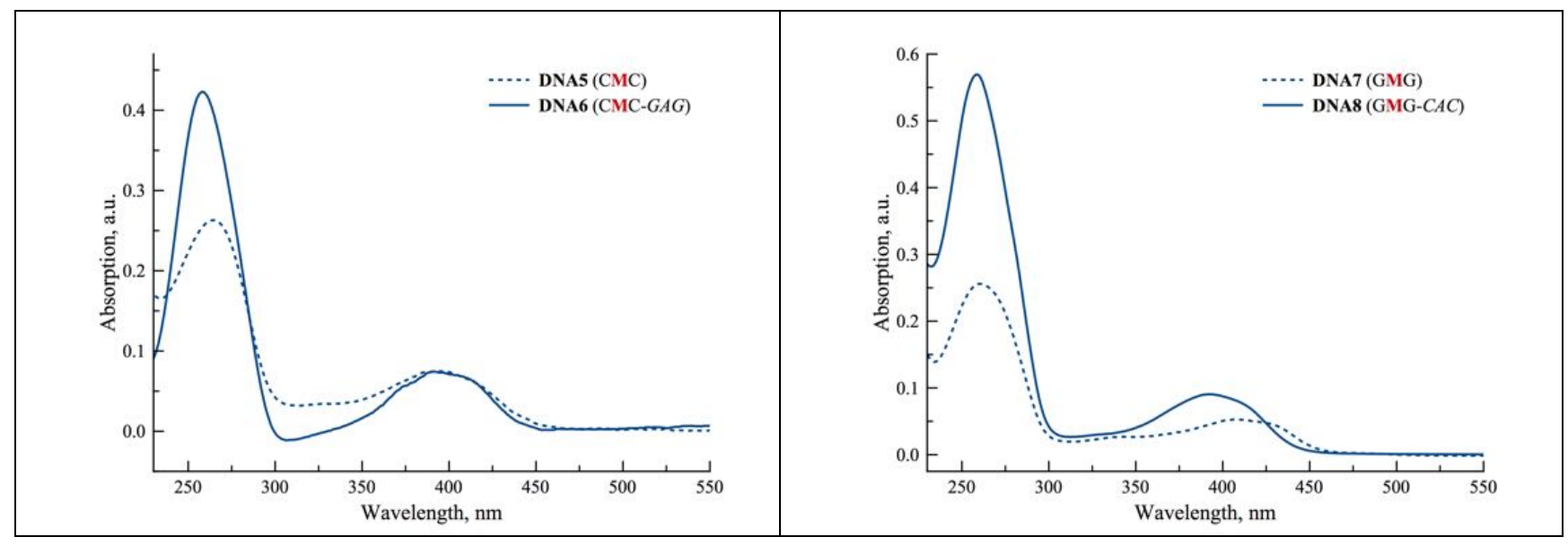

Fig S13. Absorbance spectra of wild-type, Cy3 mono- and double-labeled duplexes

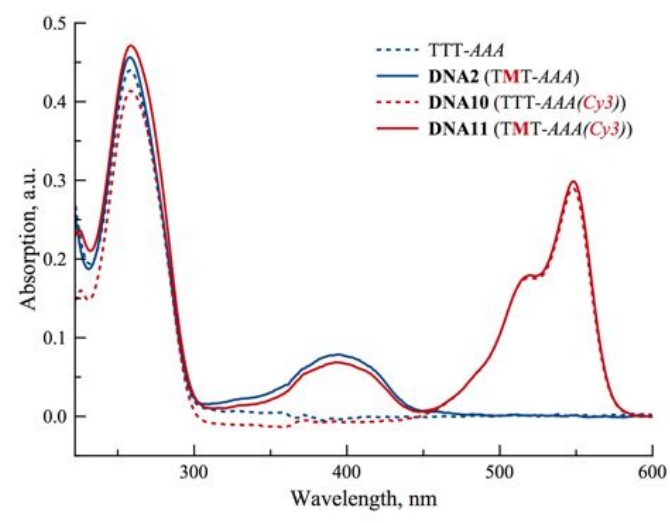

Fig S14. Fluorescence spectra of labeled single and match double strands

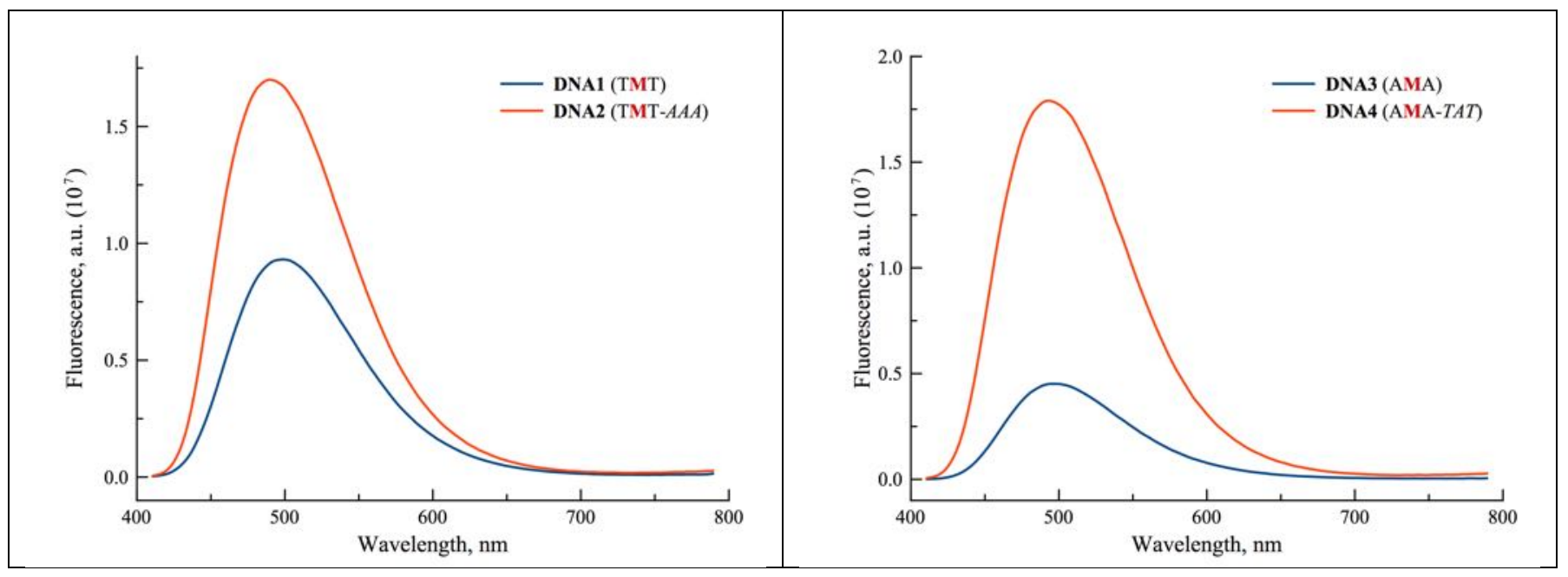




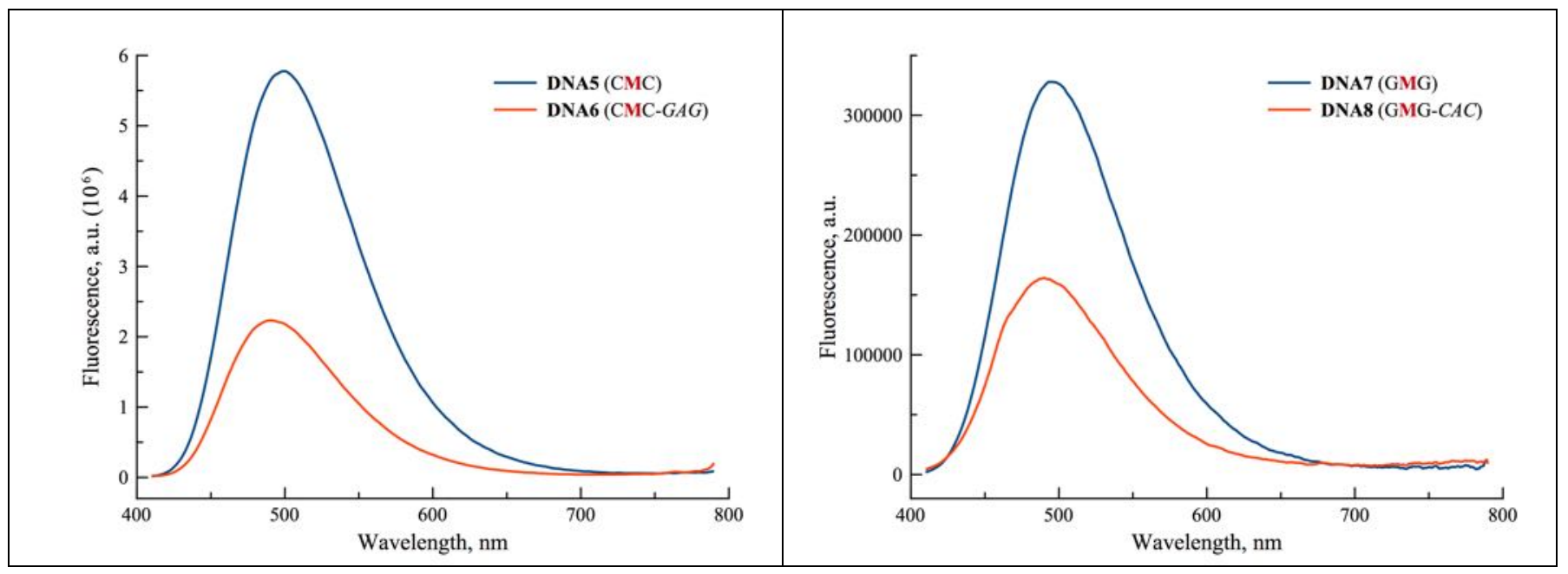

Fig S15. Photostabilities of labeled sequences and comparative references ${ }^{2}$

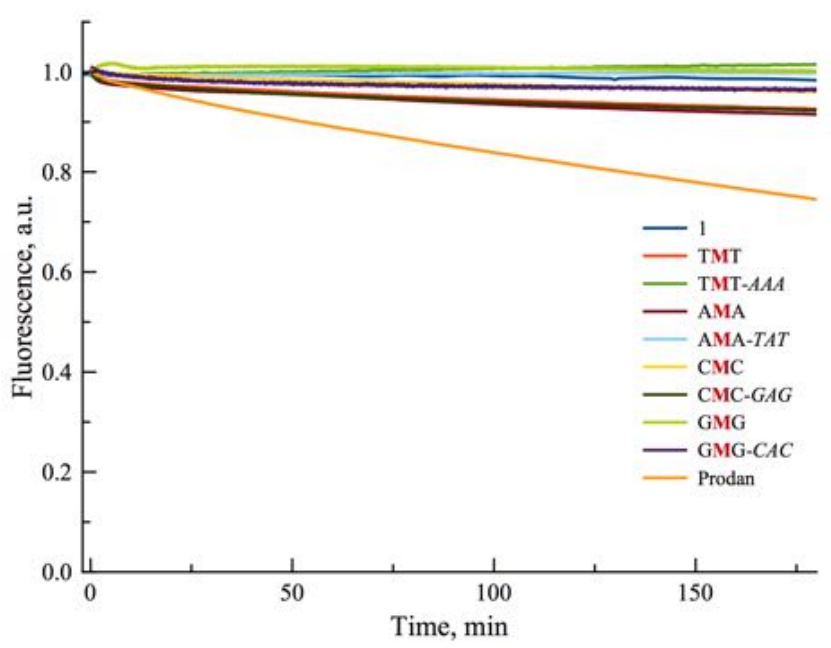

Fig S16. Exponential fittings for photodegradation curves

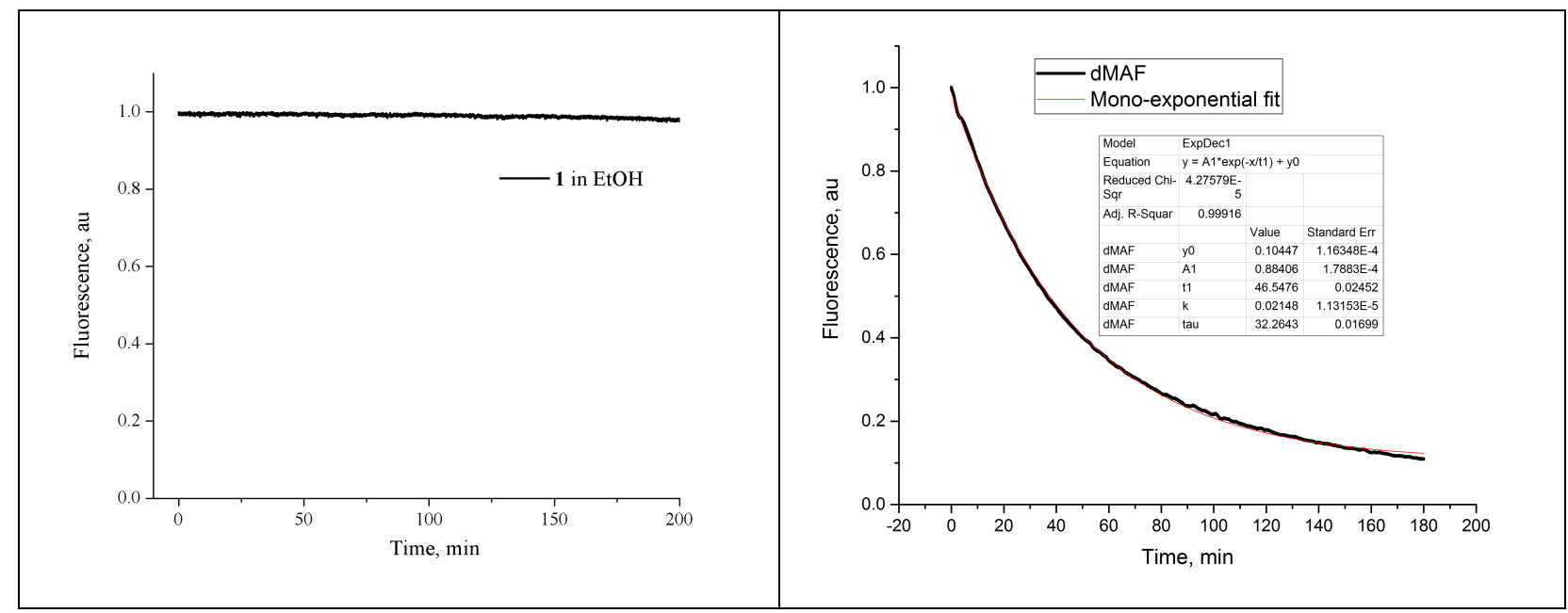

${ }^{2}$ PRODAN applied to DNA labeling: (a) Tainaka, K.; Tanaka, T.; Ikeda, S.; Nishiza, K.-I.; Unzai, T.; Fujiwara, Y.; Saito, I.; Okamoto, A. J. Am. Chem. Soc. 2007, 129, 4776. (b) Okamoto, A.; Tainaka, K.; Unzai T.; Saito, I. Tetrahedron 2007, 63, 3465. (c) Kimura, T.; Kawai K.; Majima, T. Chem. Commun. 2006, 1542. 


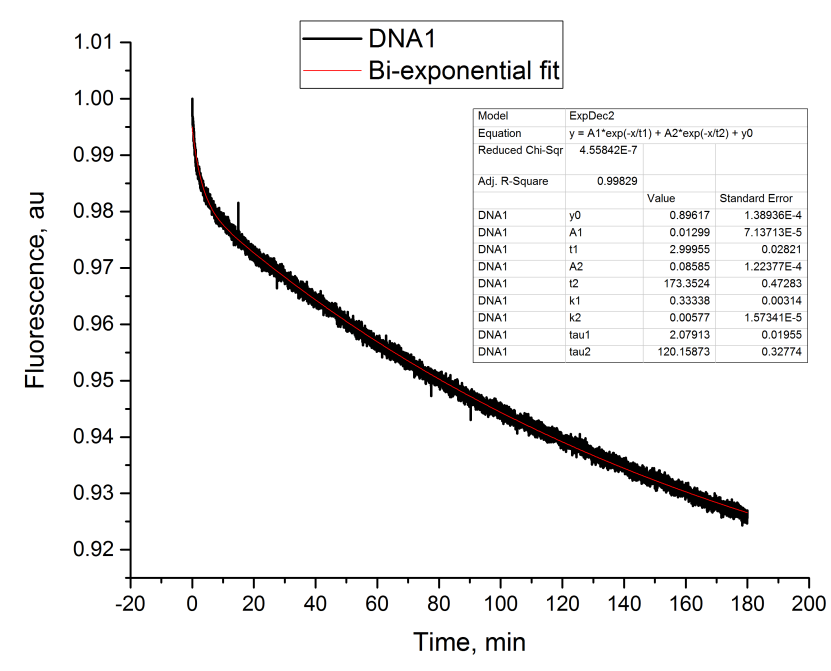

Fig S17. Excitation spectra of DNA10 and DNA11 collected at $490 \mathrm{~nm}$ (A) and at $564 \mathrm{~nm}(\mathrm{~B})$
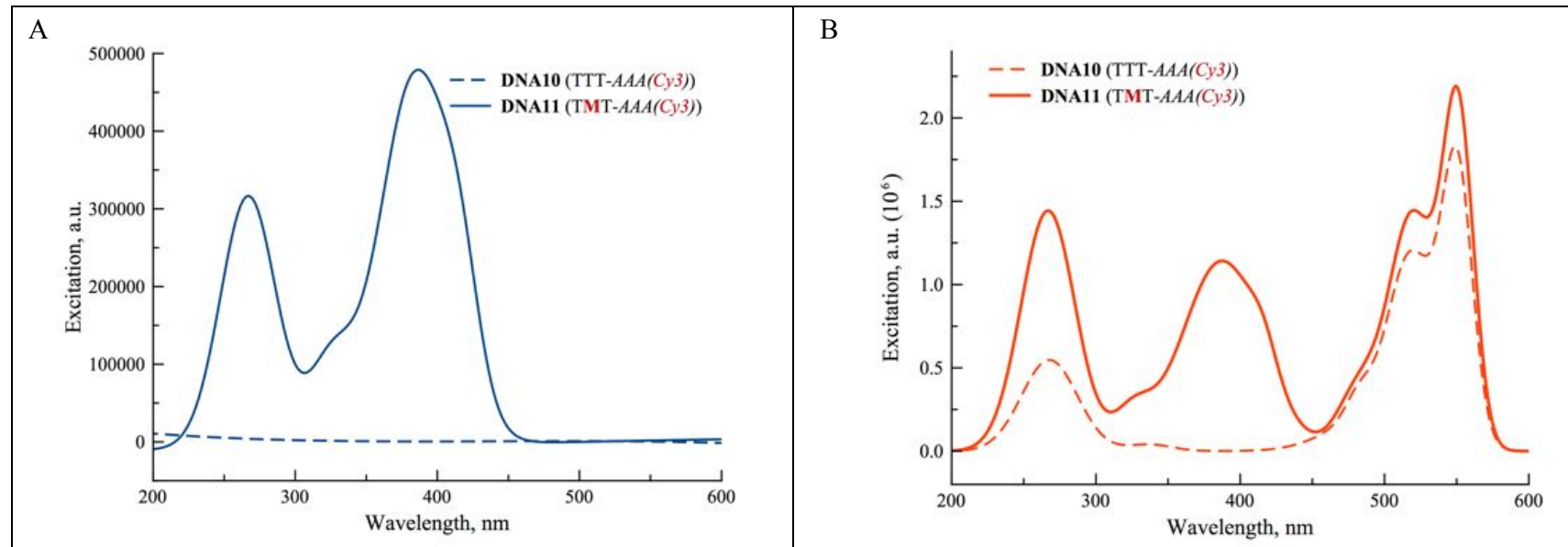

Fig S18. Fluorescence titration of DNA1 with DNA9 (normalized by the donor emission band on the right)

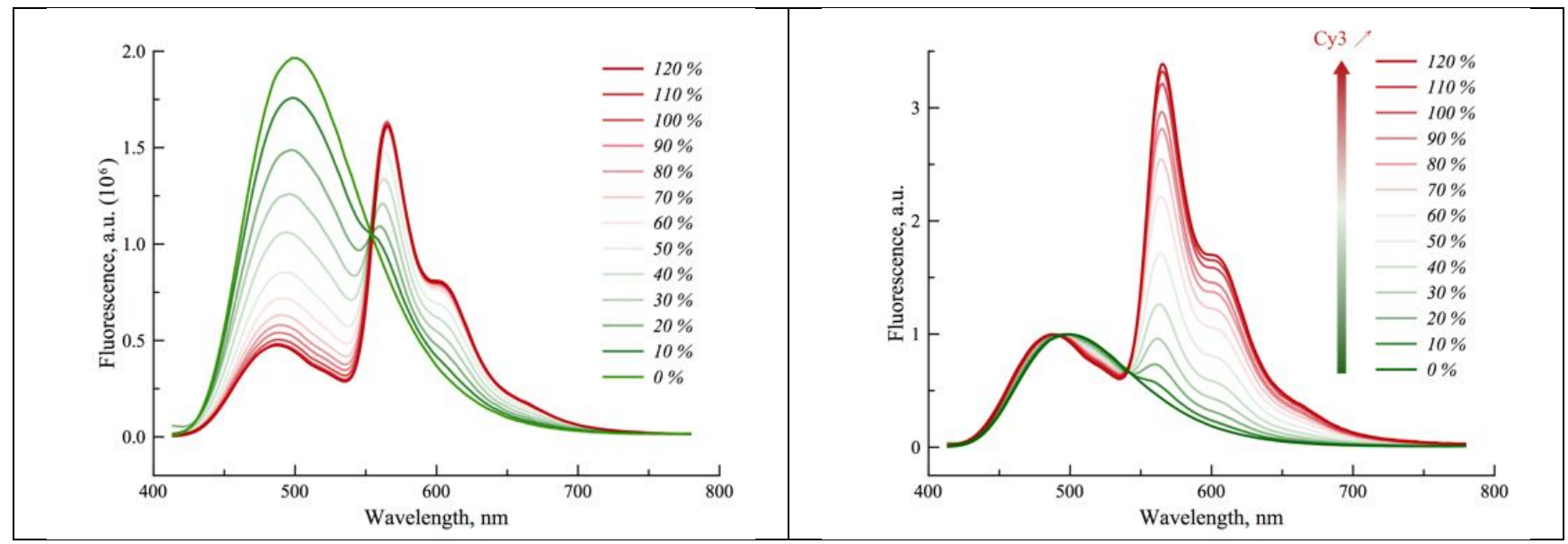


Fig S19. S/B ratio vs. [DNA9]

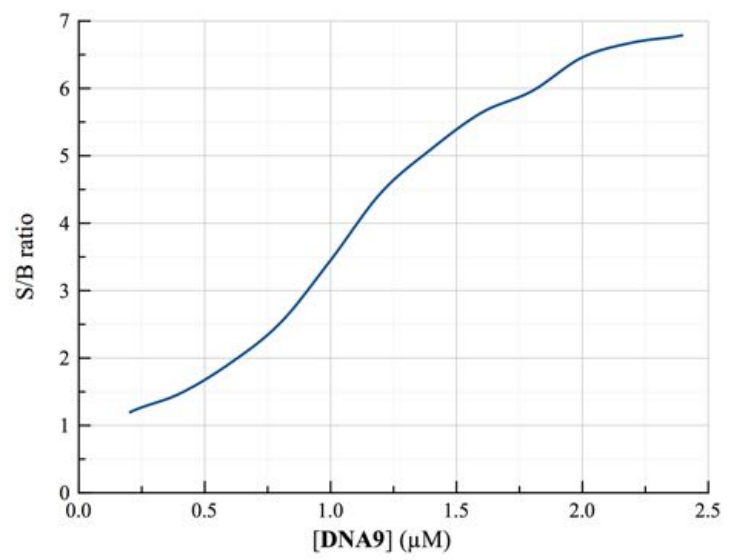

a) Plot of S/B ratio $\left[\left(I_{490 \mathrm{i}} / I_{564 \mathrm{i}}\right) /\left(I_{490 \mathrm{t}} / I_{564 \mathrm{t}}\right)\right]$ vs. the concentration of DNA9 at fixed DNA1 concentration $(\mathbf{2} \boldsymbol{\mu M})$, « $\mathrm{i} »$ and $« \mathrm{t} »$ indicate respectively initially and over the titration.

\section{NMR spectra}




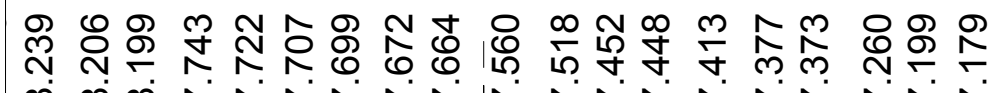

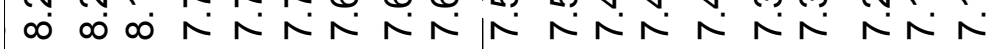

\section{$5^{1} \mathrm{H}$ NMR}

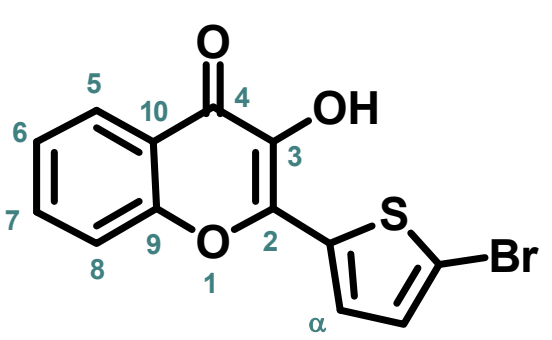

$\mathrm{CHCl}_{3}$

Ha

\begin{tabular}{ll|l}
$\mathrm{H} 7$ & $\mathrm{H} \beta$
\end{tabular}

H8

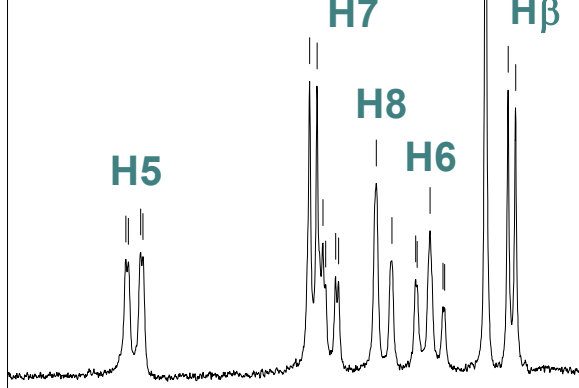

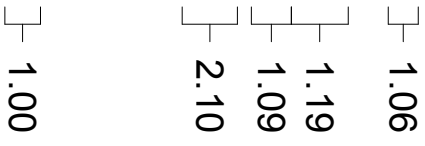




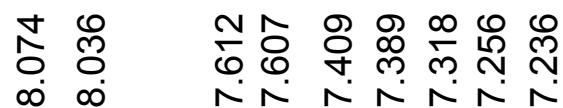

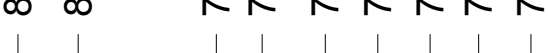

\section{$5^{\mathbf{1}} \mathrm{H} \mathrm{NMR}$}
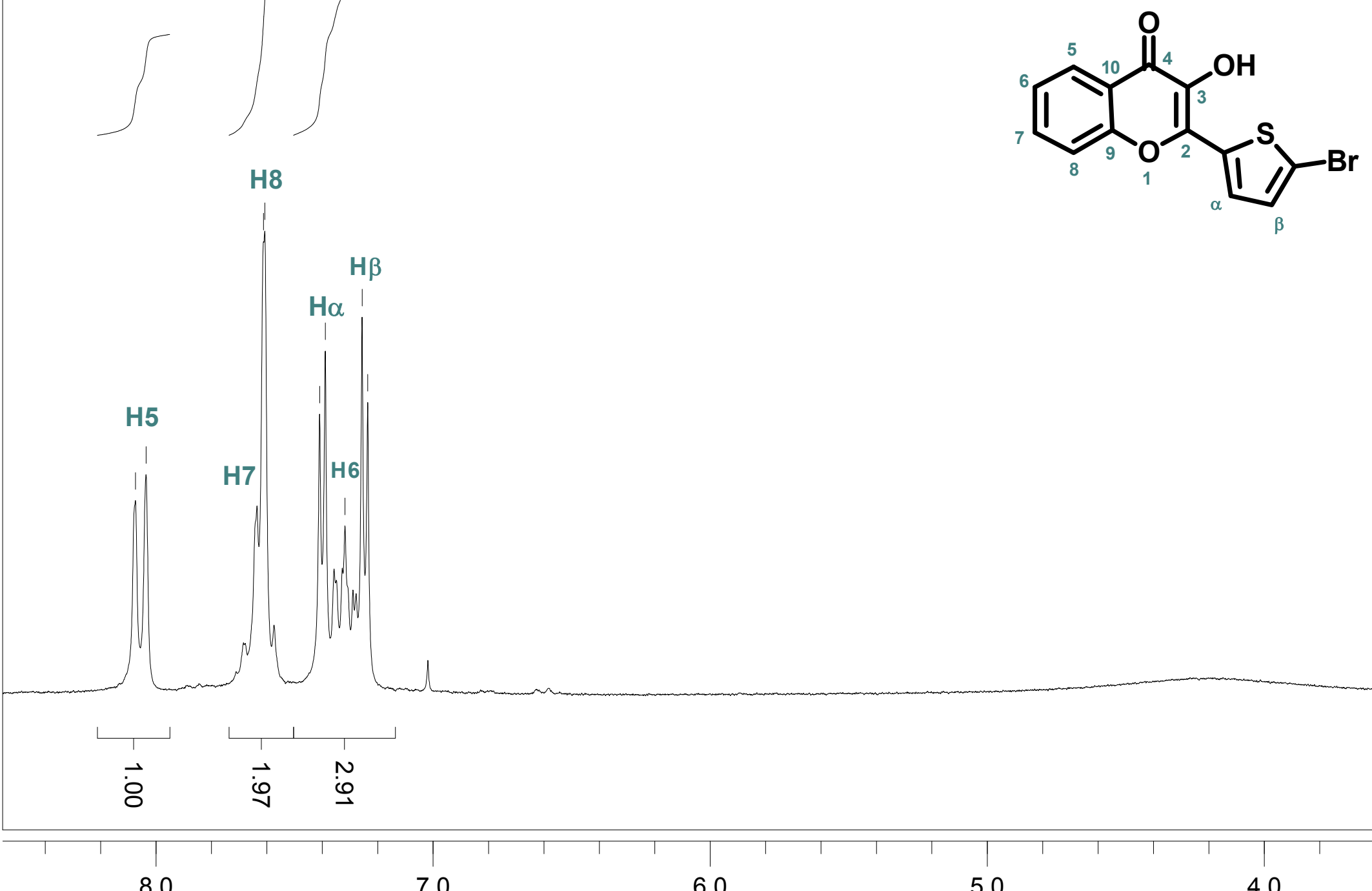

ppm (t1) 


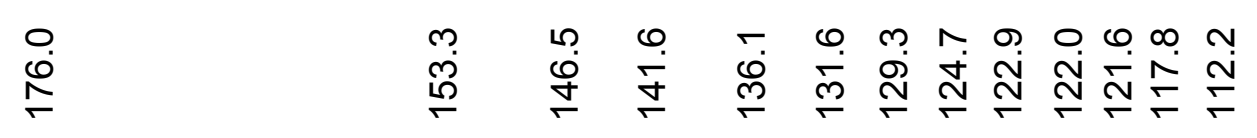

家

${ }^{13} \mathrm{C}$ NMIR

DMSO
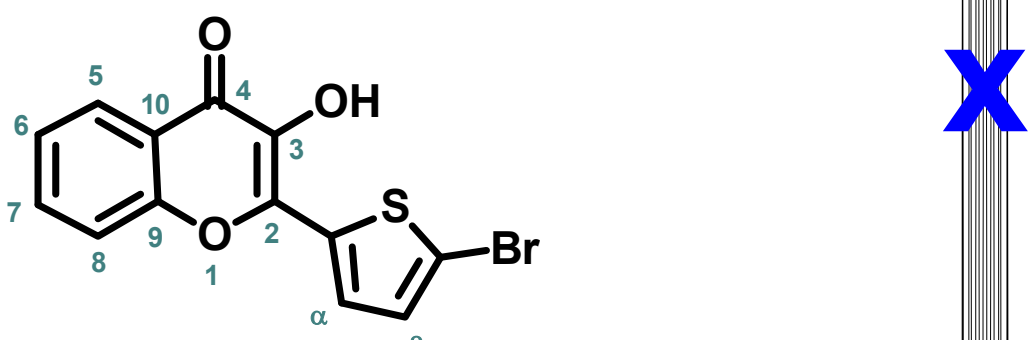

WW

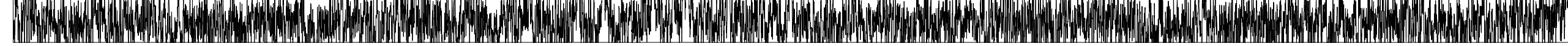

$$
\stackrel{\mathrm{C}_{\beta}}{\mathrm{C} 6} \mathrm{C}
$$

c9

$$
\mathrm{C}_{\alpha}
$$

C4 


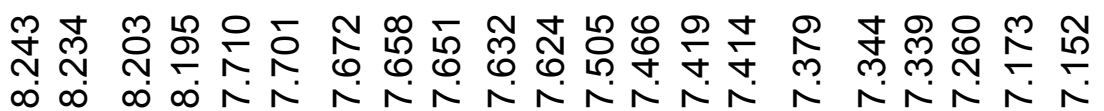

${ }_{6}{ }^{1} \mathrm{H}$ NMR

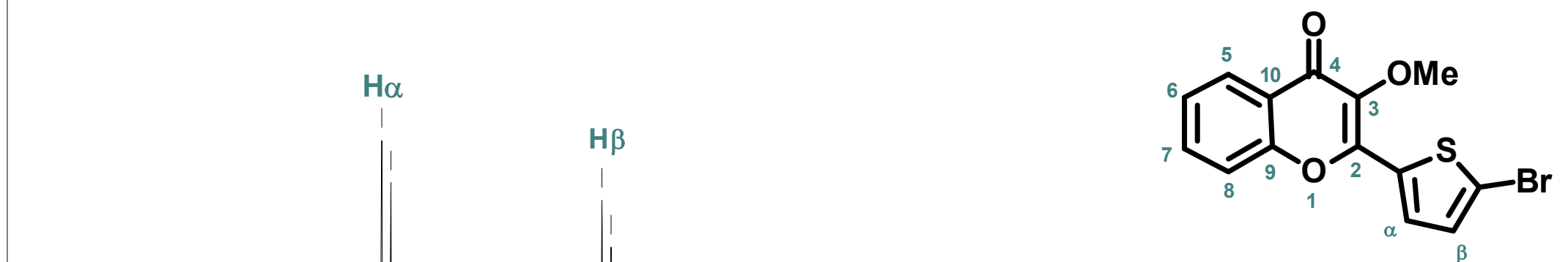

H5

$\mathrm{H} 8 \mathrm{CHCl}_{3}$

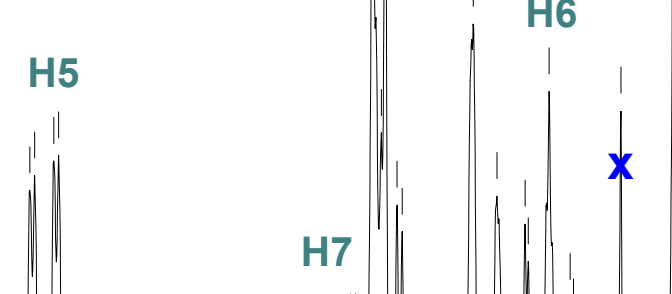

$\overrightarrow{\mathrm{s}}$

苔 $\vec{i} \vec{i} \stackrel{\circ}{\circ}$

$\ddot{8}$ 


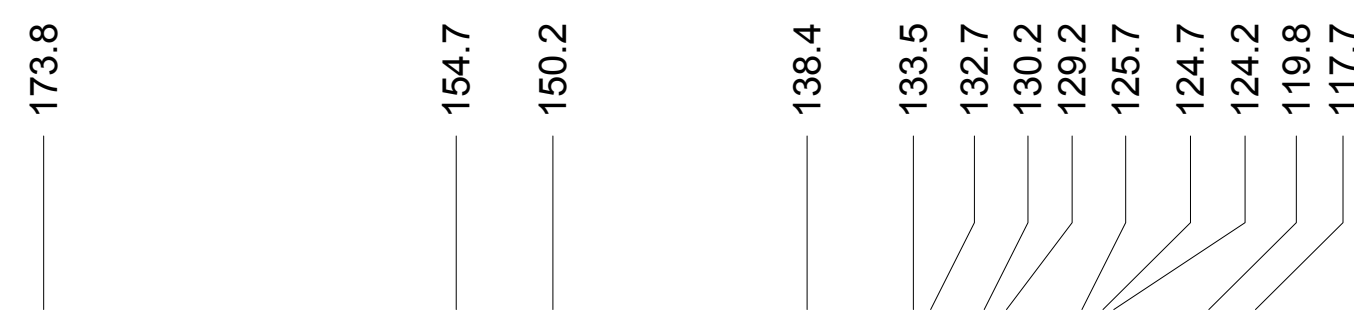

${ }^{13} \mathrm{C}$ NNIR<smiles>COc1c(-c2ccc(Br)s2)oc2ccccc2c1=O</smiles>

$\mathrm{CDCl}_{3}$
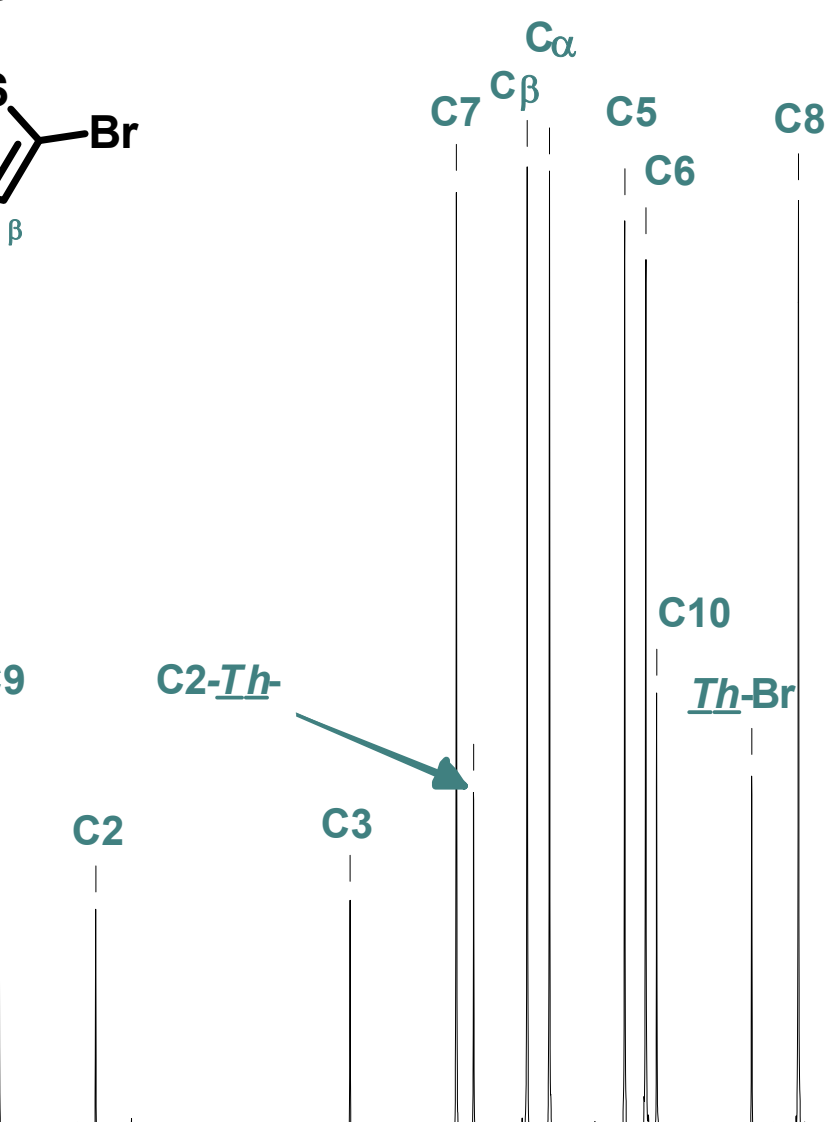

C8

OMe

C4

C9

C2 


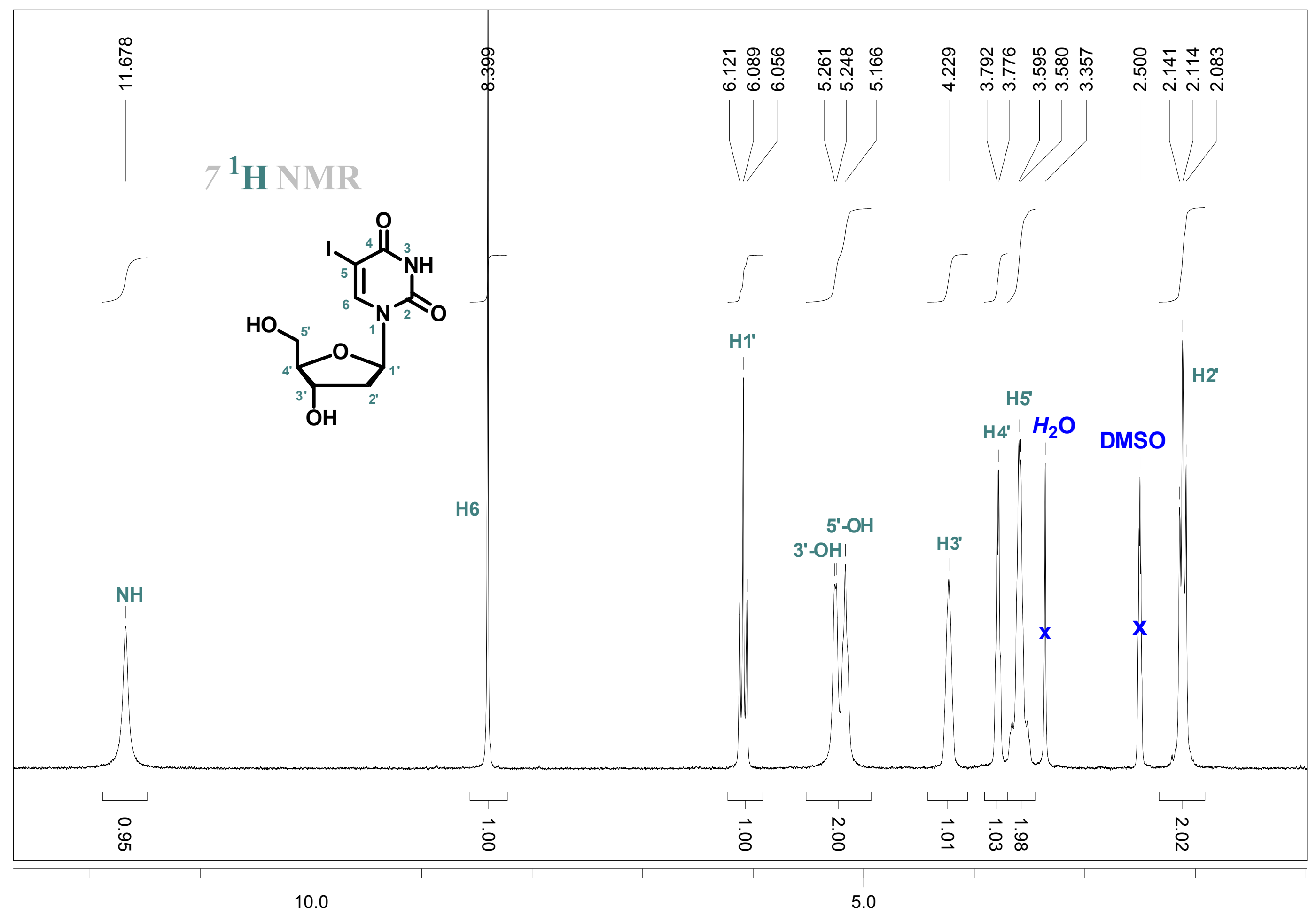



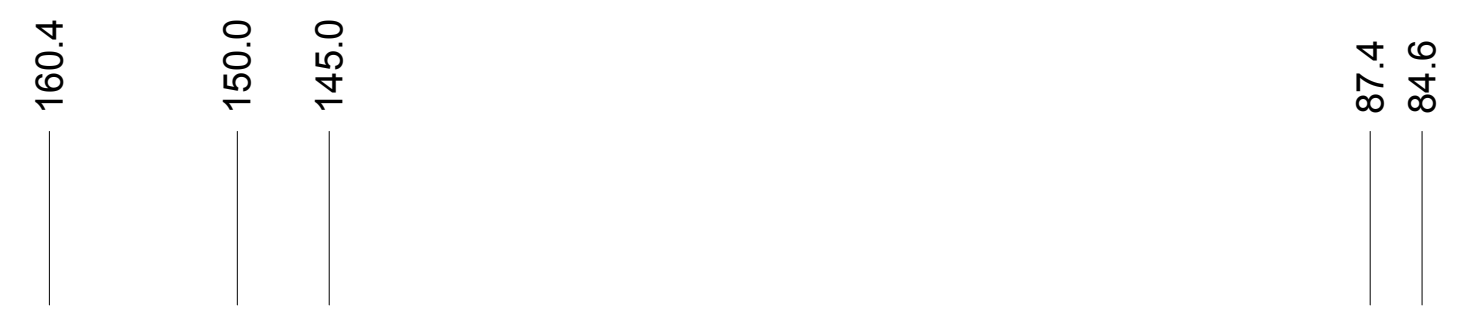

용 웅

$\hat{8}$

${ }^{73} \mathrm{C}$ NMR<smiles>O=c1[nH]c(=O)n([C@@H]2[CH][C@@H](O)[C@@H](CO)O2)cc1I</smiles> 


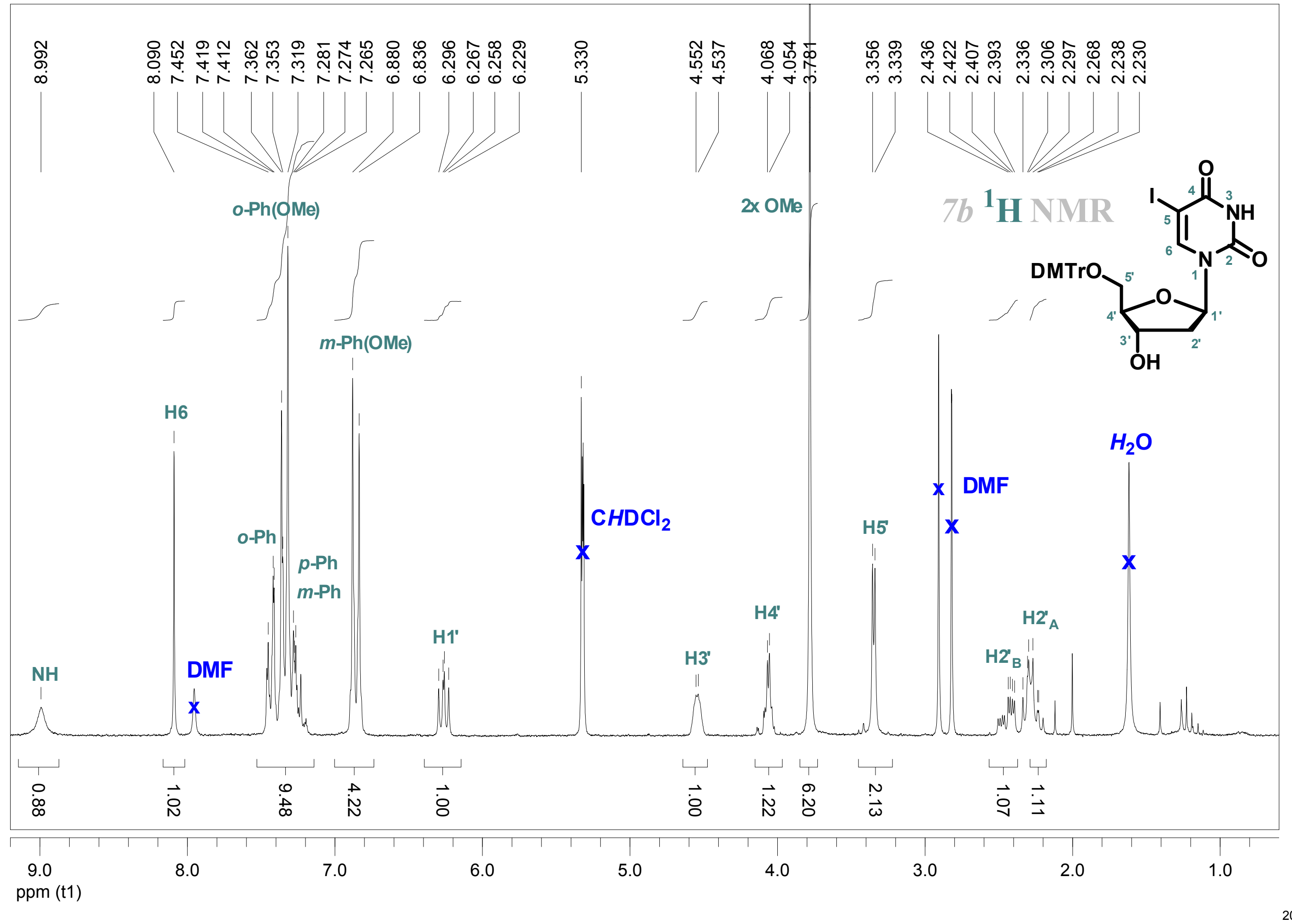




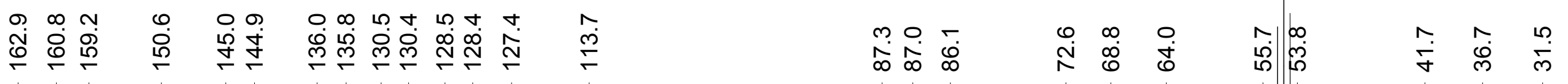

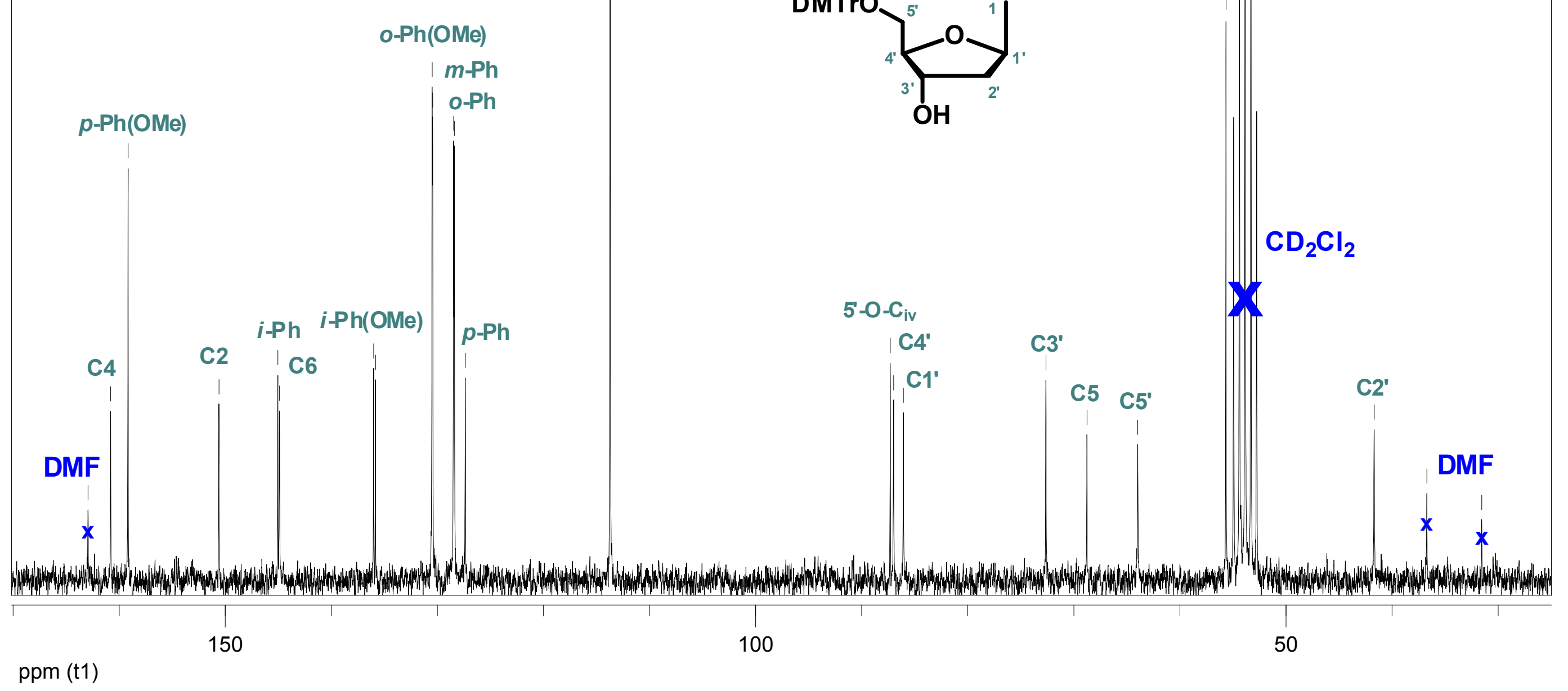




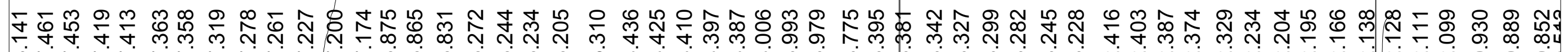

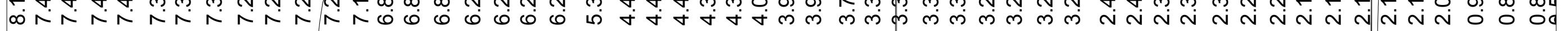
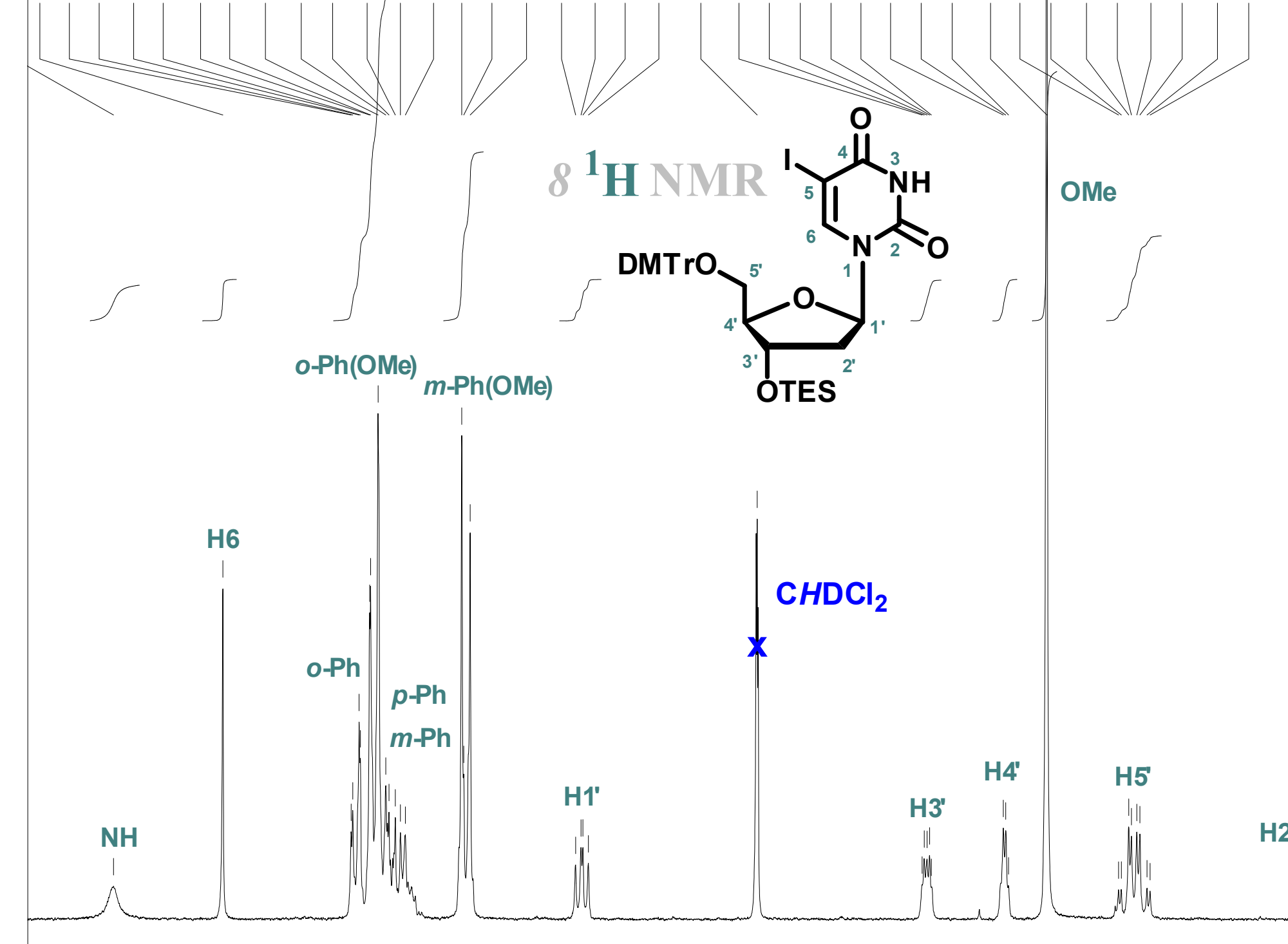

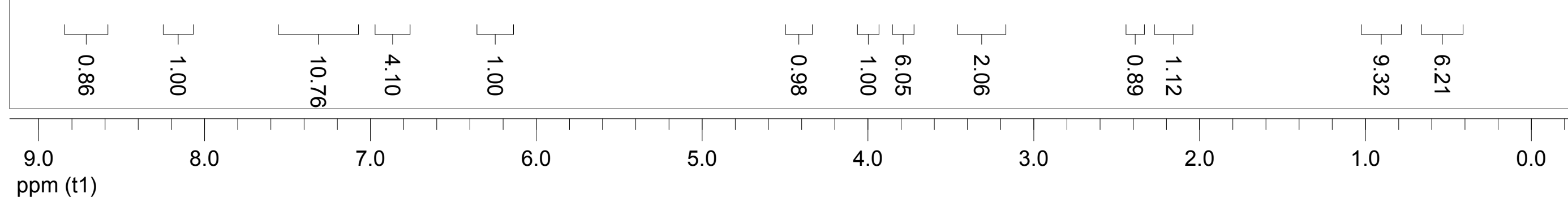




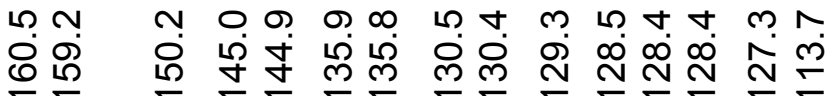

$\infty$ ก.

कि

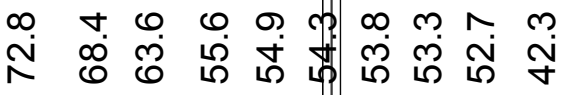

$\stackrel{\infty}{0} \stackrel{\infty}{\dot{\gamma}}$

$r$ r r r r
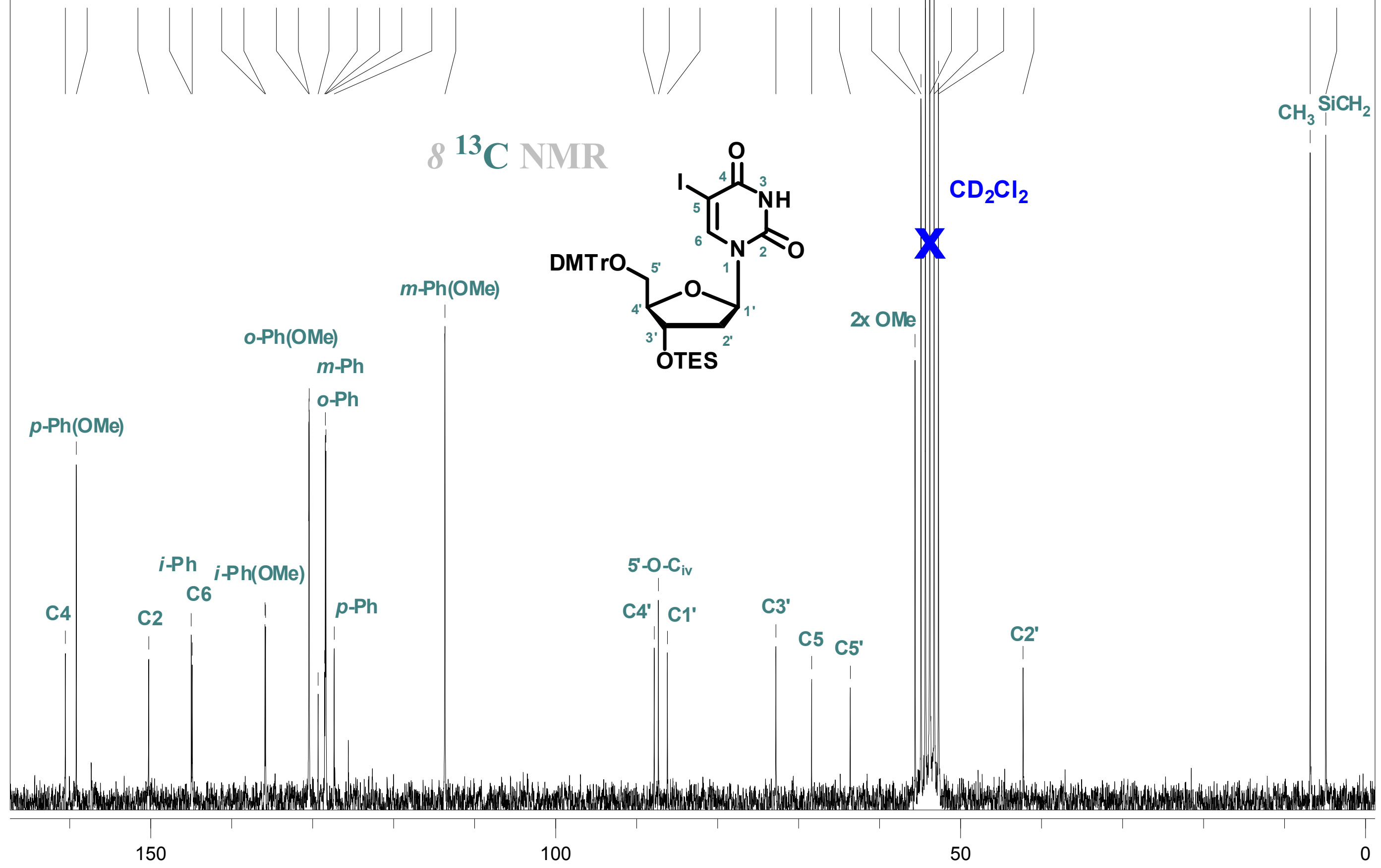


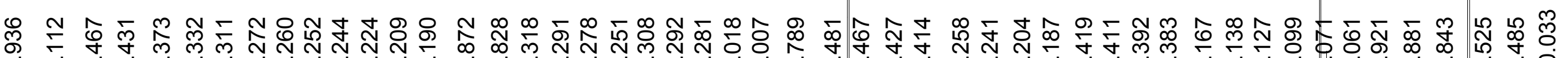
車

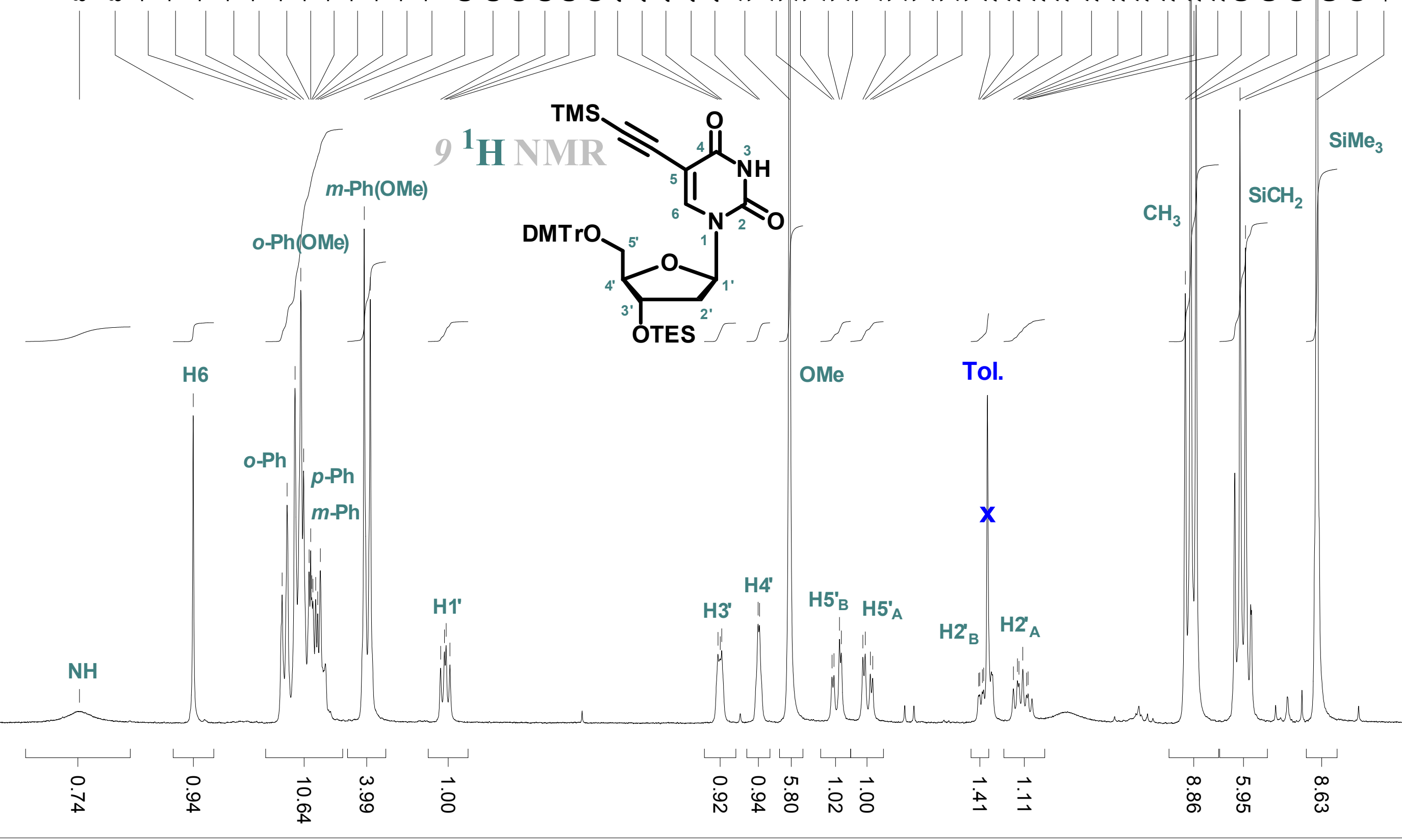




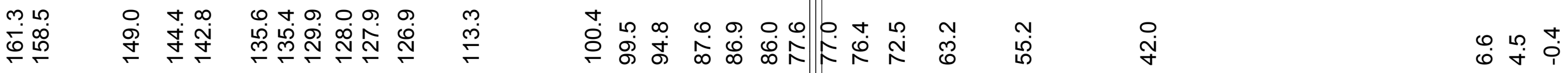
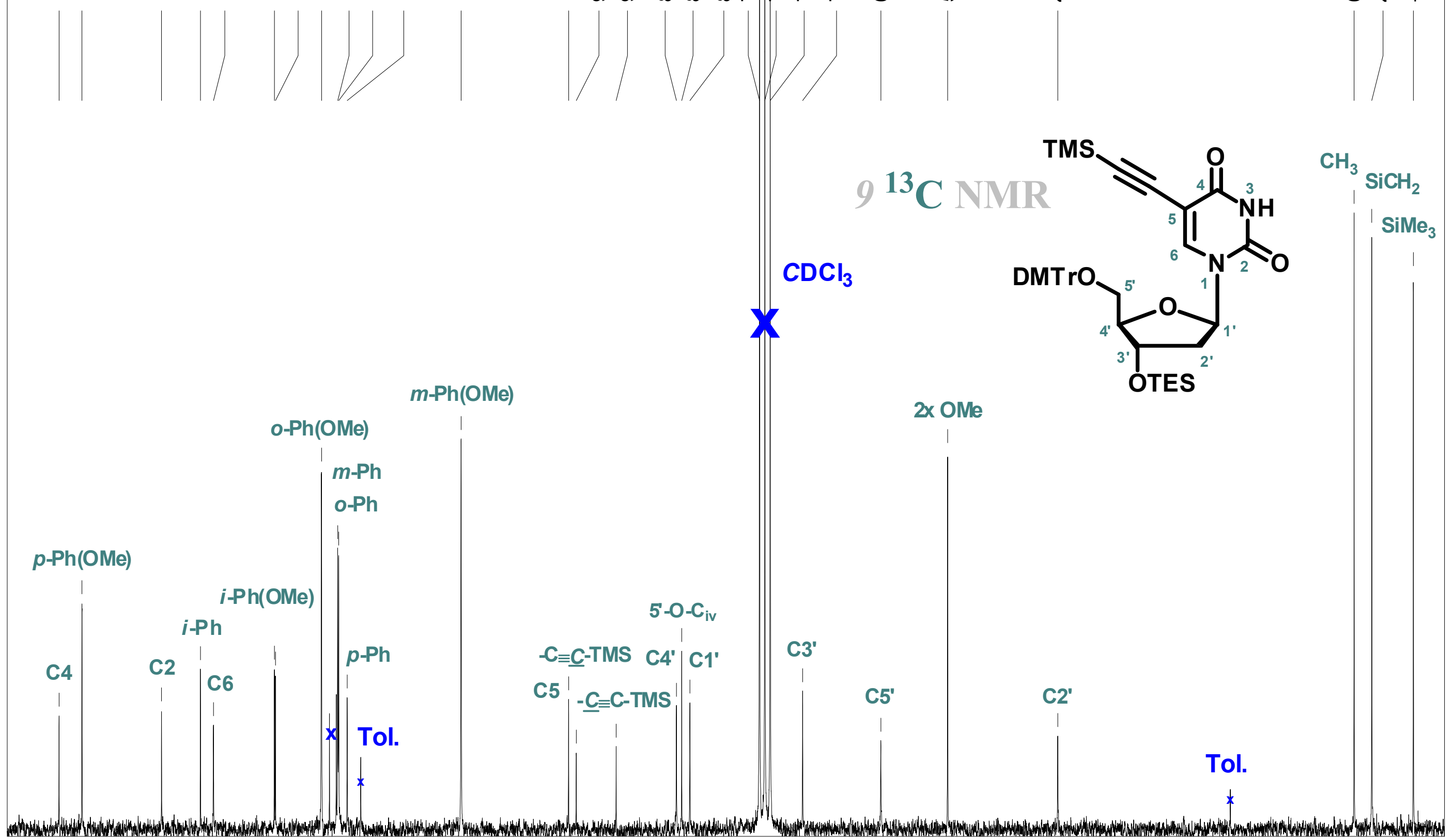


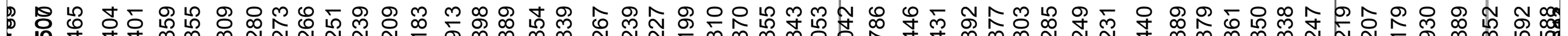

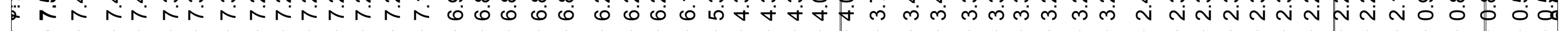

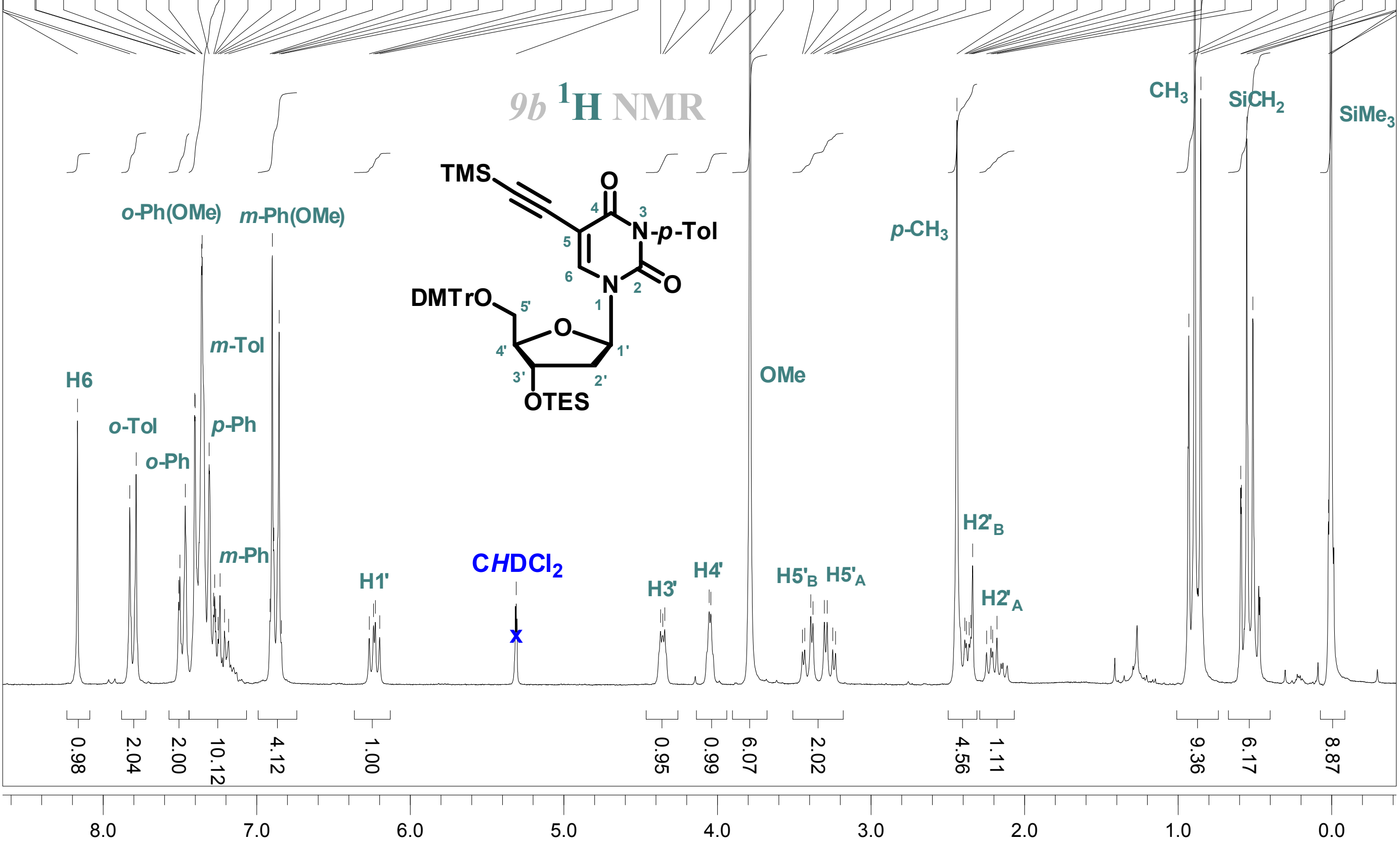




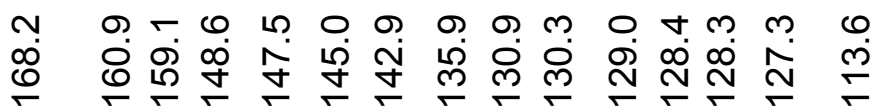

வ்

$\stackrel{\overbrace{}}{i} \quad \stackrel{0}{0}$

เọ

$\stackrel{\text { \& }}{\mathfrak{4}}$

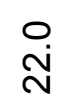

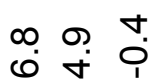
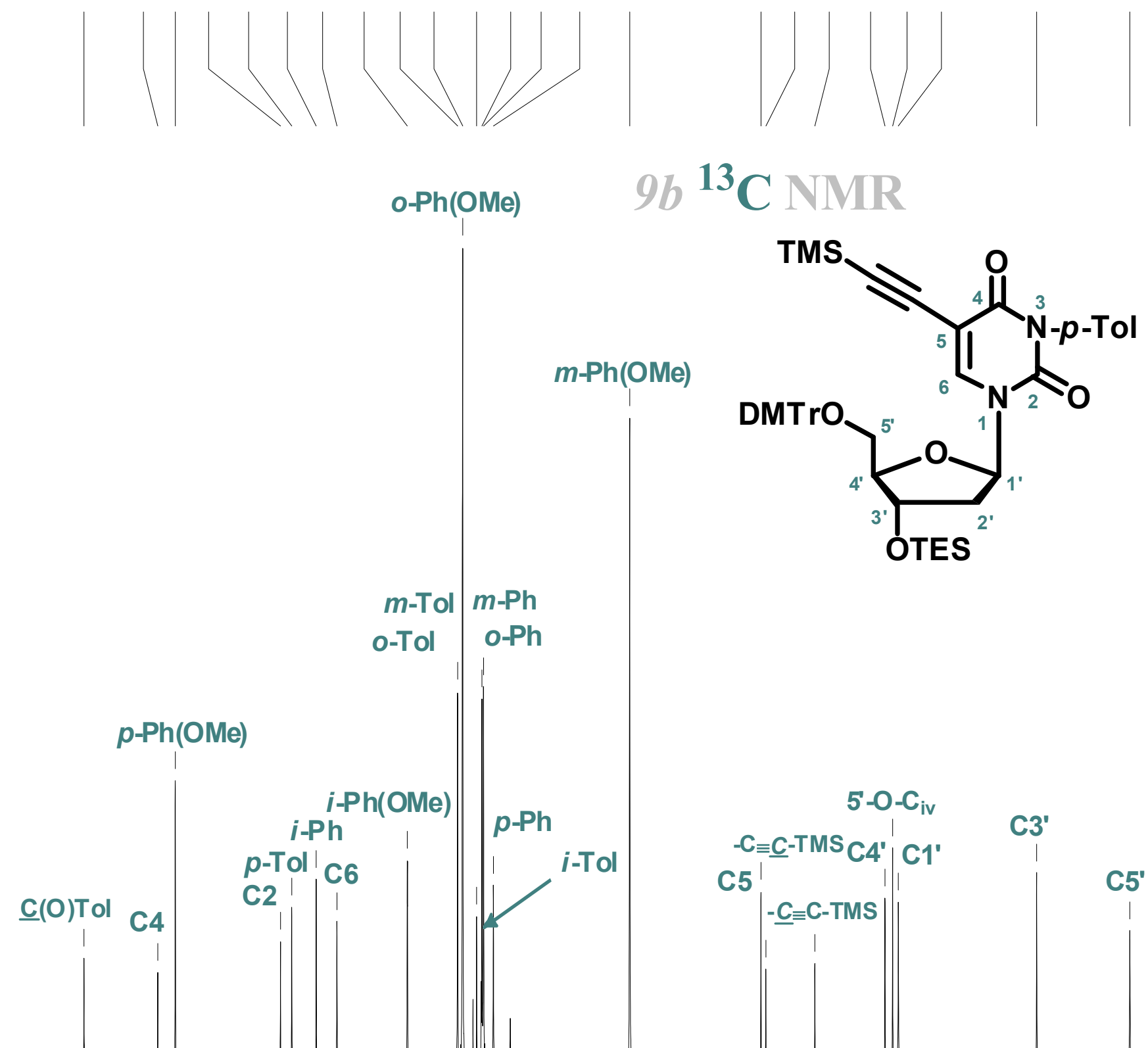

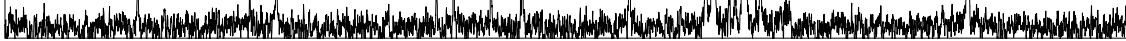


Г⿳亠丷厂巾 め

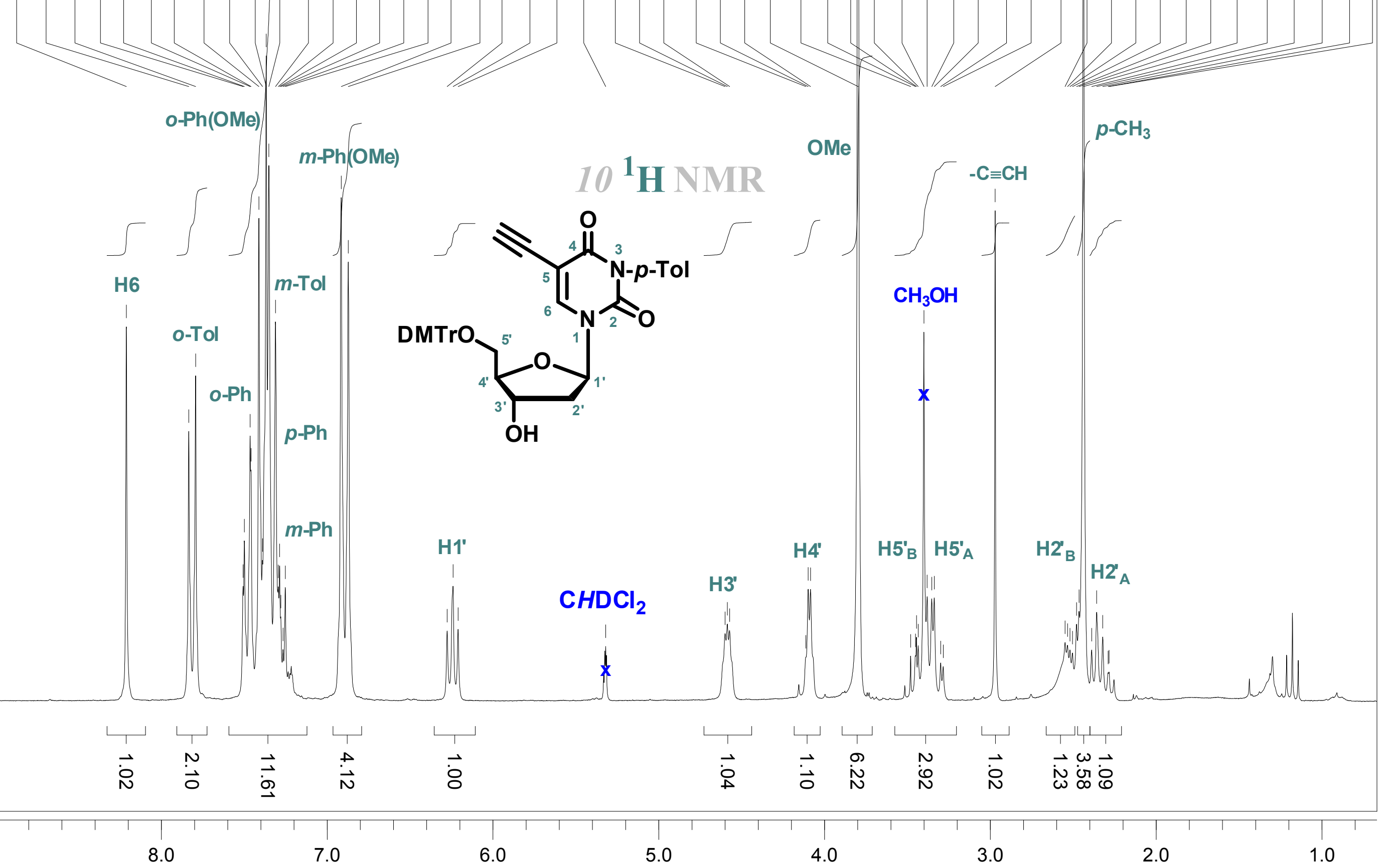




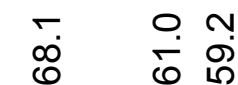

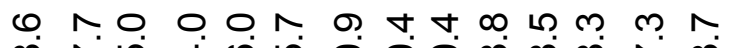

ق

p-Ph(OMe)

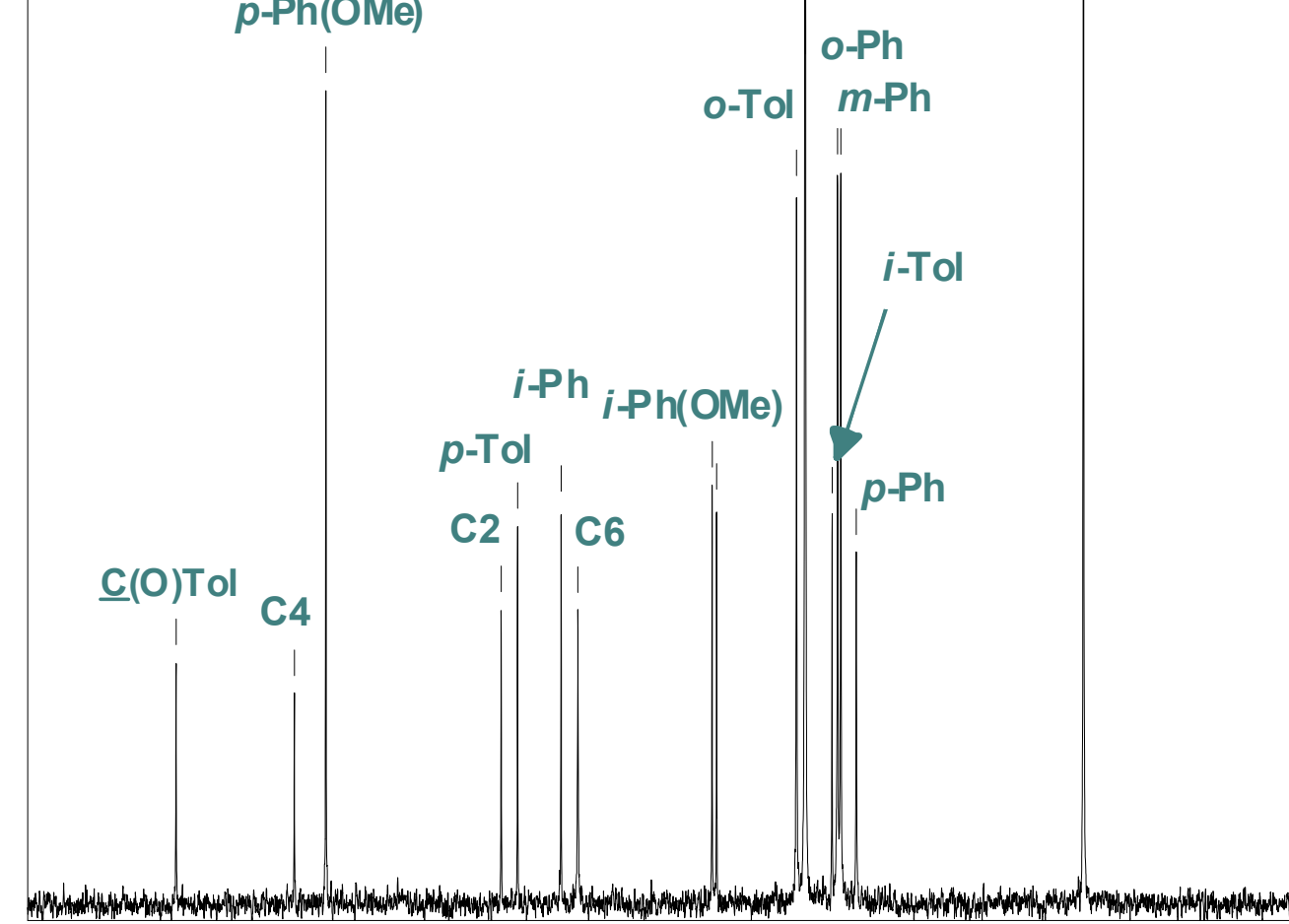

m-Ph(OMe)

\section{0}

13 C NNR

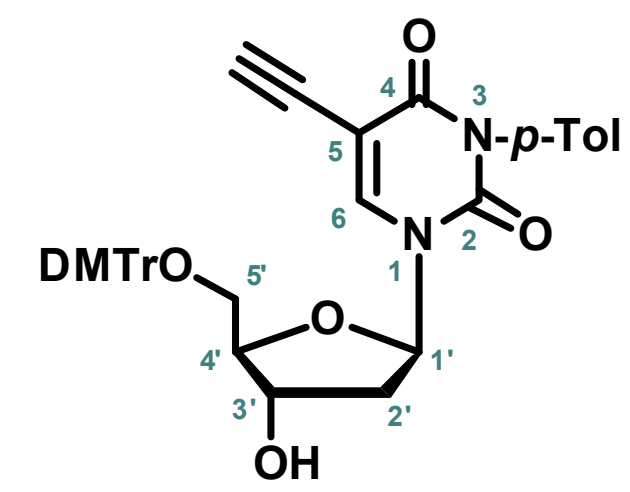

C5

5'-O-C

C4'

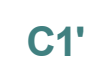

$-\mathrm{C} \equiv \underline{\mathrm{C}} \mathrm{H}$

C3'
$\mathrm{CD}_{2} \mathrm{Cl}_{2}$

C2' 


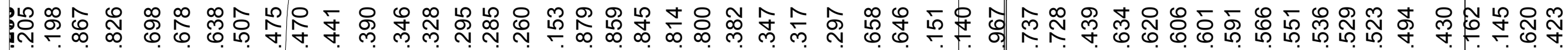

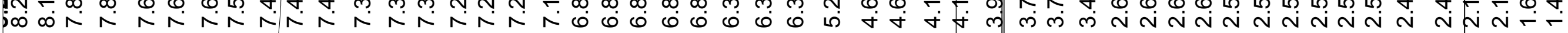

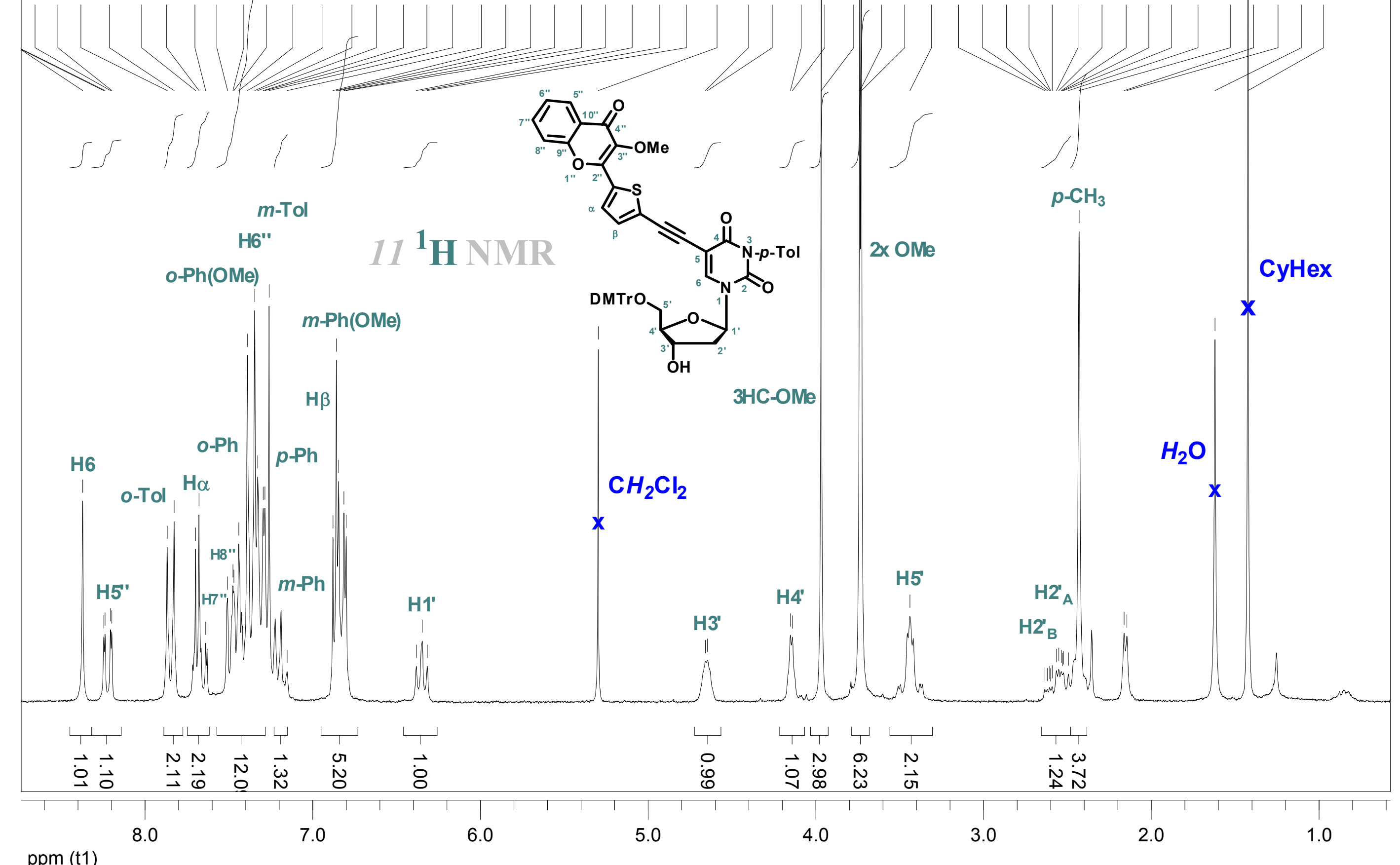




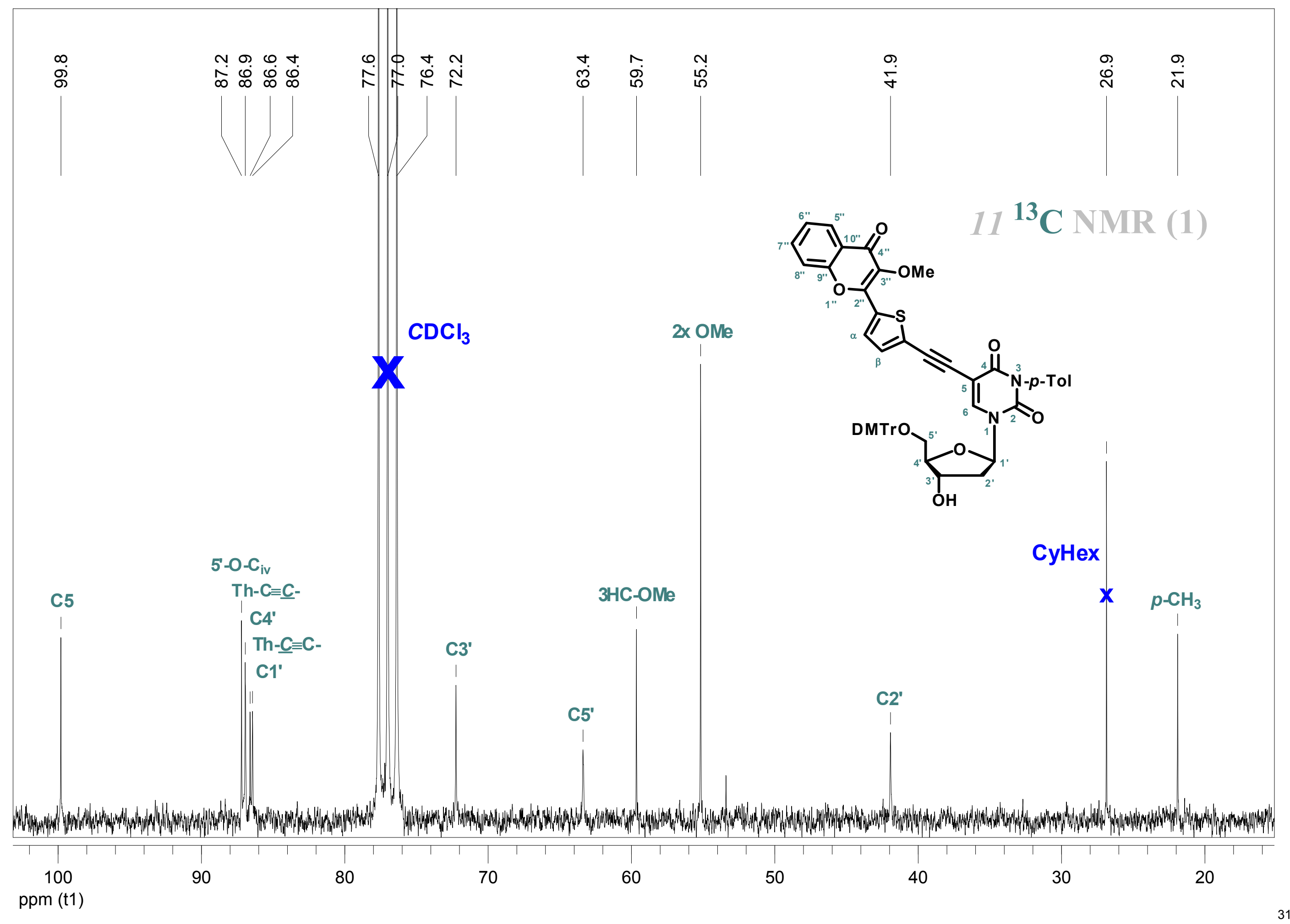




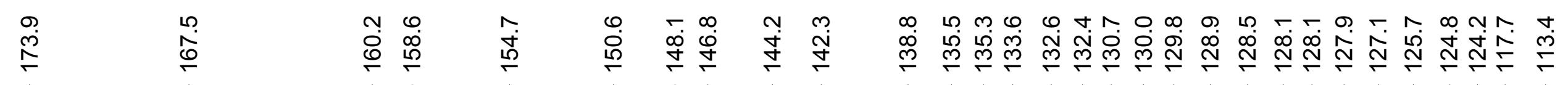
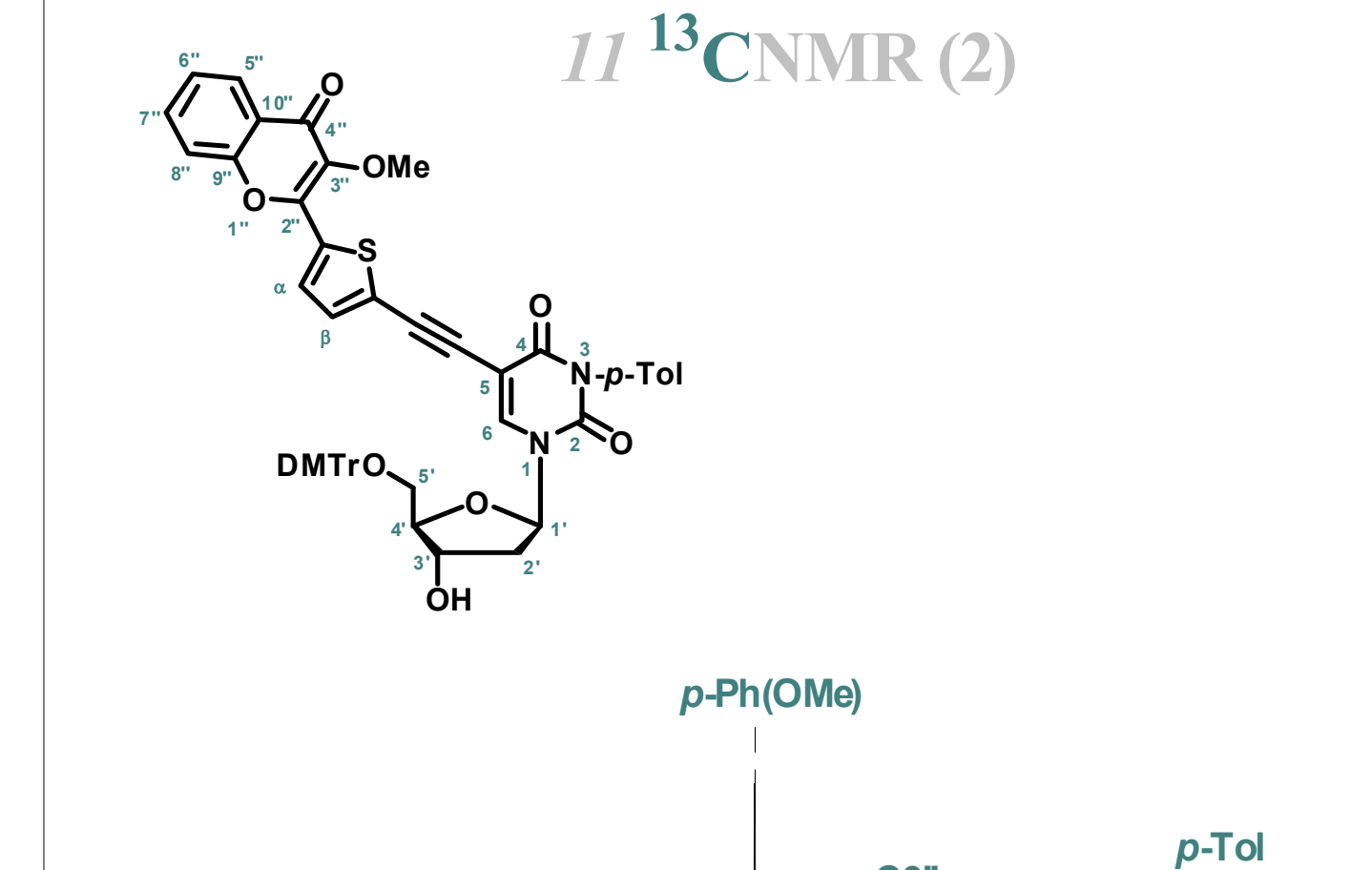

$c 4^{\prime \prime} \quad \underline{c}(0)$ Tol

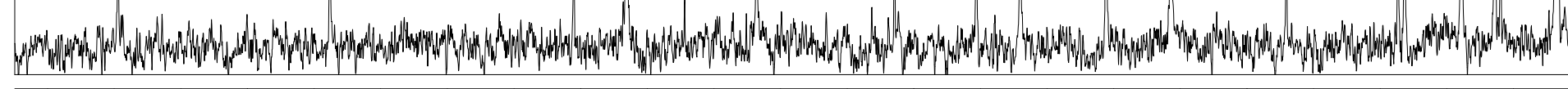

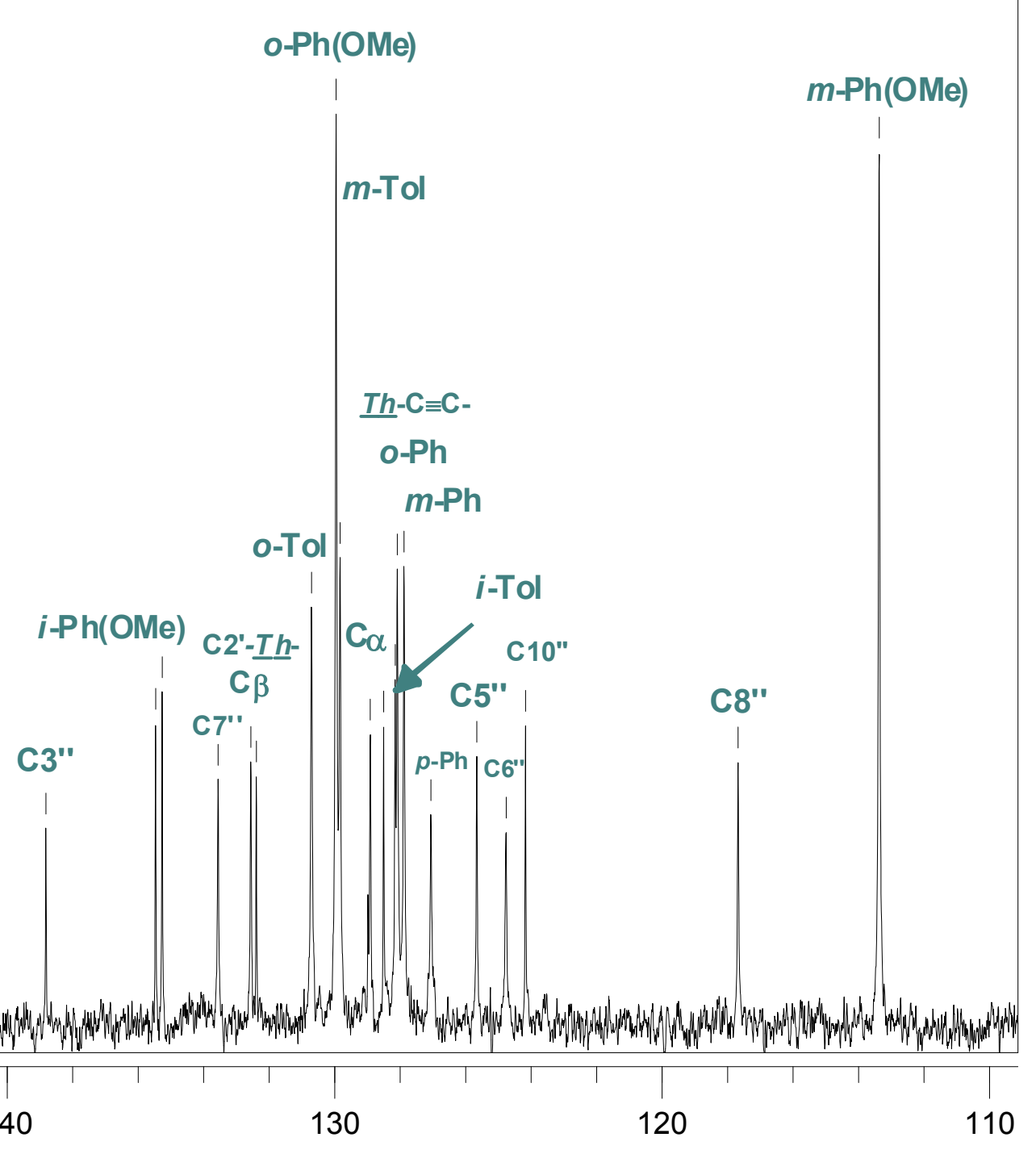

ppm (t1)

160

150

140

130 


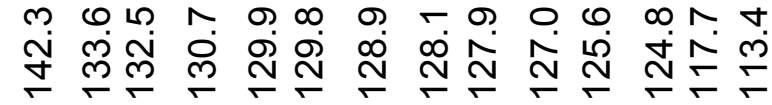

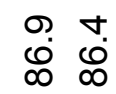

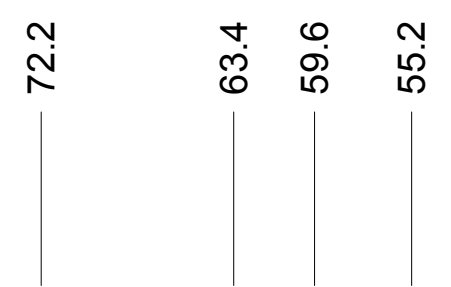

$\stackrel{\dot{q}}{\check{g}}$

$\stackrel{\infty}{\stackrel{\infty}{*}} \stackrel{\infty}{\grave{N}}$
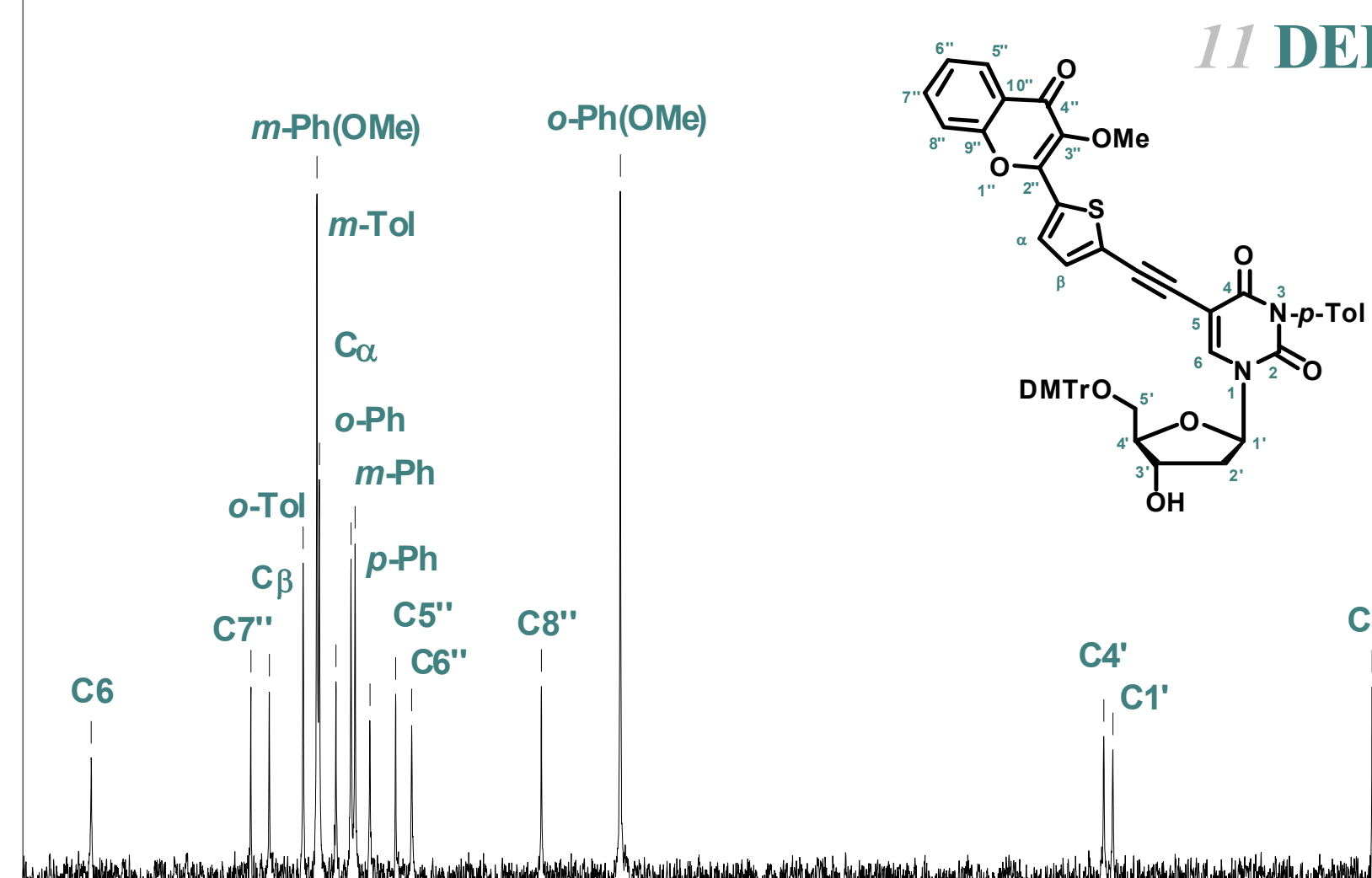

2x OMe

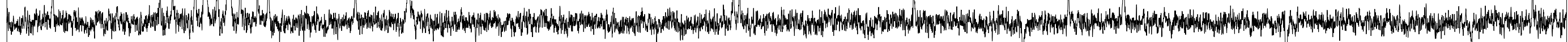

C8"<smiles>CCCI</smiles> 


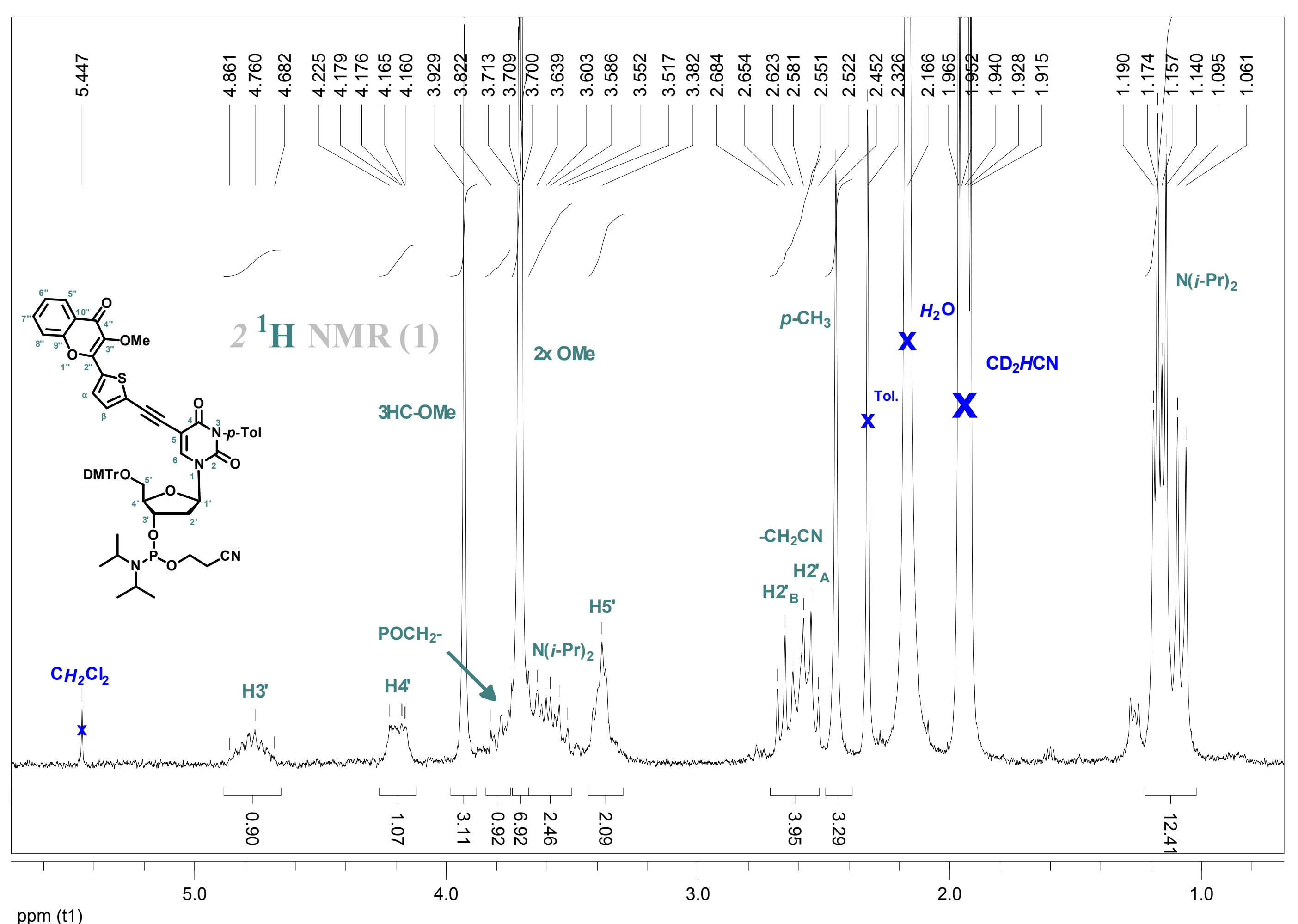




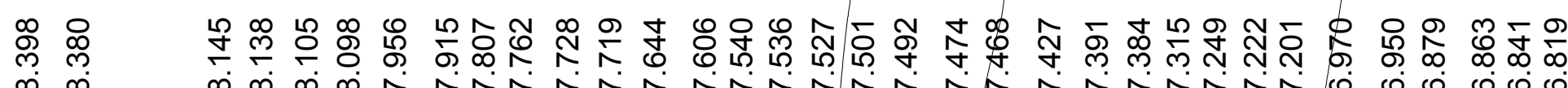
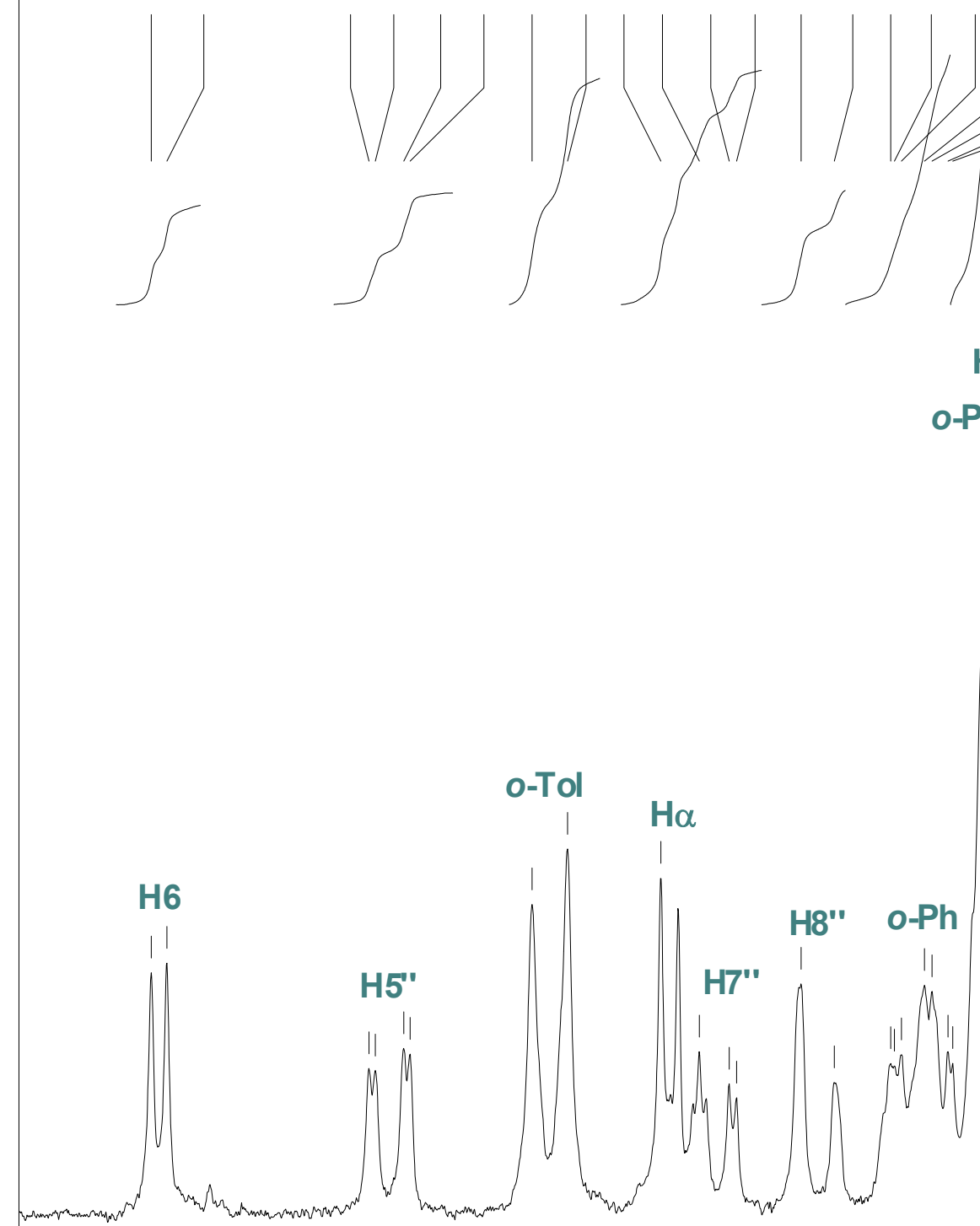

\section{${ }_{2}^{1} \mathrm{H}$ NMR (2)}

H6"

o-Ph(OMe)

m-Tol

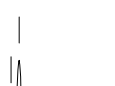

Tol.
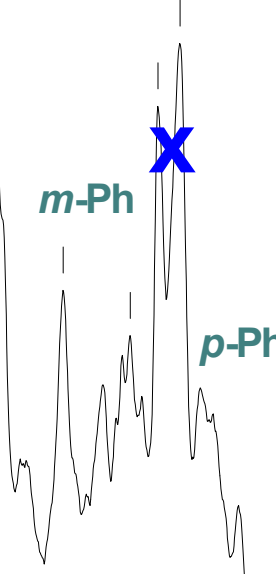

$m-\mathrm{Ph}(\mathrm{OMe})$

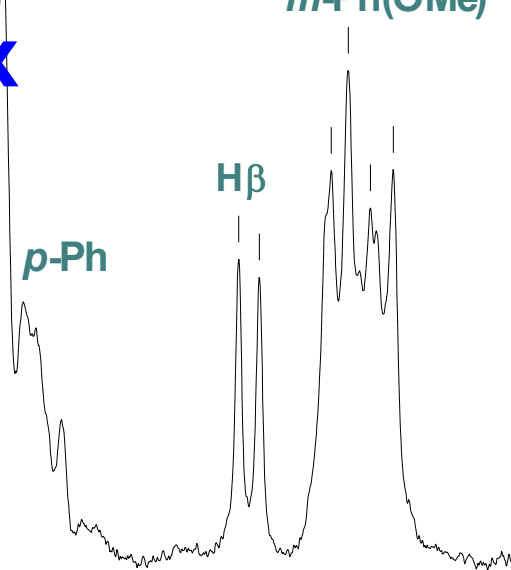

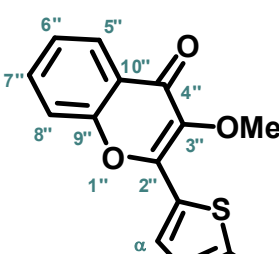

is

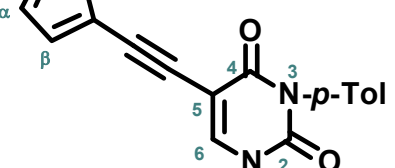

DMTrO

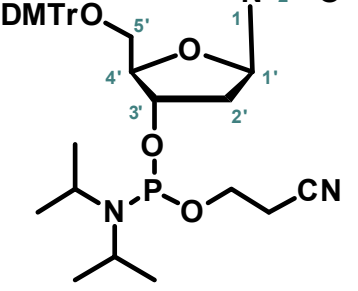

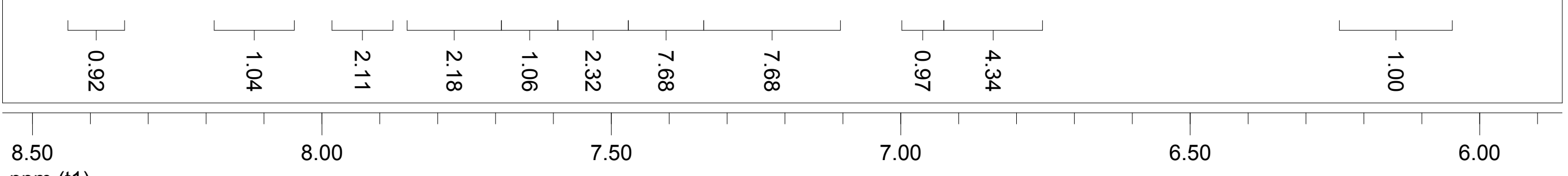




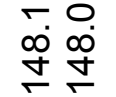

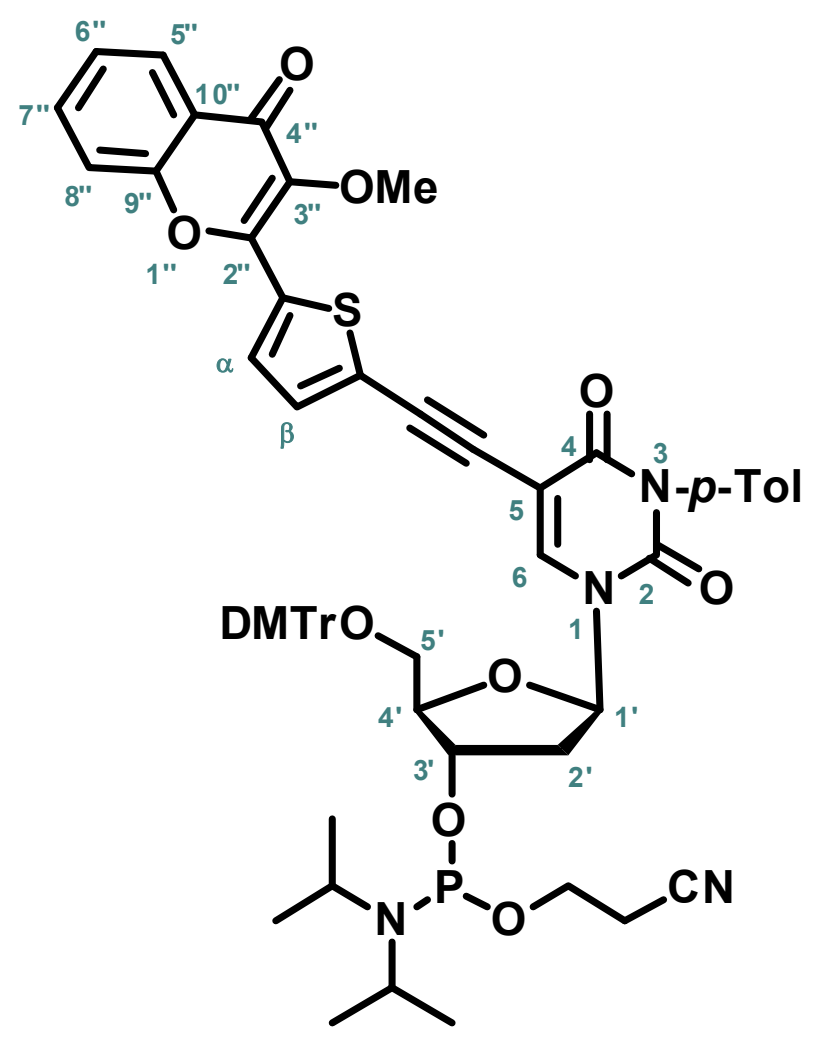

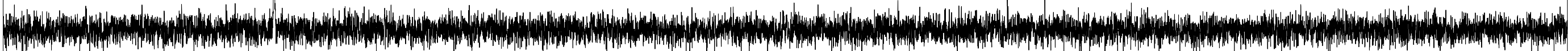

